\title{
O Que nos Faz Humanos? Bases Empíricas e Evolutivas das Principais Transições da Linhagem Hominínia
}

[What Makes us Human? Empirical and Evolutionary Bases of the Main Transitions of Hominin Lineage]

\section{Pedro Da-Glória*}

Resumo: A evolução da linhagem humana é um assunto de alta relevância para o entendimento da morfologia e do comportamento de humanos modernos. Todavia, no Brasil há pouca produção bibliográfica sobre o assunto e uma carência na formação de alunos versados sobre esse tópico. Em continuidade aos esforços feitos por pesquisadores como Paulo Abrantes, este texto trabalha com as principais transições na linhagem hominínia, do momento de seu aparecimento há cerca de sete milhões de anos na África até o surgimento do Homo sapiens há 200 mil anos. A evolução humana é organizada aqui em três grandes transições. A primeira delas foi o surgimento da bipedia e a diminuição dos caninos. A segunda foi o surgimento das ferramentas de pedra, a expansão do cérebro e a diminuição dental. E, a terceira transição foi o surgimento do pensamento simbólico. Esses tópicos são abordados em uma perspectiva evolutiva, dando ênfase para evidências empíricas atuais sobre o assunto. Por fim, a evolução humana é um tópico relevante para se discutir o papel da biologia e da cultura em nossa espécie, sendo que ambas foram atuantes no processo evolutivo de formação da nossa espécie.

Palavras-chave: evolução humana; teoria da evolução biológica; anatomia humana; adaptação biocultural; registro fóssil. 


\begin{abstract}
The evolution of the human lineage is a highly relevant subject for understanding the morphology and behavior of modern humans. However, in Brazil there is little bibliographical production on the subject and a lack of training of students about this topic. In continuity with the efforts made by researchers like Paulo Abrantes, this text deals with the main transitions in the hominin lineage, from the moment of its appearance about seven million years ago in Africa until the appearance of Homo sapiens 200 thousand years ago. Human evolution is organized here in three great transitions. The first one was the appearance of bipedal locomotion and the diminution of canines. The second was the emergence of stone tools, brain expansion and dental decrease. And, the third transition was the emergence of symbolic thinking. These topics are addressed in an evolutionary perspective, with emphasis on current empirical evidence on the subject. Finally, human evolution is a relevant topic to discuss the role of biology and culture in our species, both of which were active in the evolutionary process of formation of our species.
\end{abstract}

Keywords: human evolution; theory of biological evolution; human anatomy; biocultural adaptation; fossil record.

\section{Introdução}

A origem e evolução das características que nos distinguem como seres humanos é uma questão extremamente relevante para o entendimento das raízes biológicas e culturais do nosso comportamento. Por outro lado, há pouca produção bibliográfica sobre o tema da evolução humana no Brasil, principalmente no que tange às conexões entre morfologia e comportamento humano. Exceções a esse panorama são os volumes editados por Abrantes (2014a) e Neves et al. (2015), que buscaram reunir material sobre o tema em língua portuguesa. Ainda mais problemático é a ausência desse tópico na formação da maioria dos alunos de graduação e pósgraduação no Brasil, o que reflete negativamente na compreensão de importantes aspectos do comportamento humano. Este texto visa contribuir para a reflexão sobre o tema da evolução humana, apresentando as bases empíricas e evolutivas dos principais traços que nos distinguem como seres humanos.

A escolha dos traços aqui elencados não pretende de forma alguma esgotar os traços definidores da humanidade, mas sim reflete discussões históricas sobre o tema, que frequentemente incluem essas características como fundamentais na transição para a humanidade. Seguindo discussões iniciadas no trabalho de Darwin (1871) e depois desenvolvidas ao longo do século XX (Tattersall, 2009), este texto abordará as seguintes carac- 
terísticas definidoras dos seres humanos: bipedia, diminuição dos caninos, fabricação de ferramentas, expansão do cérebro, diminuição dental e pensamento simbólico. Além do aspecto histórico, a escolha desses traços também é devida à relativa facilidade com que eles podem ser reconhecidos no registro paleoantropológico, seja através dos fósseis ou da cultura material. Neste texto, esses traços são organizados em três grandes transições, que sintetizam a compreensão recente da sequência de eventos envolvidos em nossa trajetória evolutiva. Essa organização não implica que a evolução humana ocorreu em três saltos discretos, já que muitas dessas características surgiram ao longo de milhões de anos em ritmos evolutivos distintos. Por outro lado, essa organização permite estruturar de forma esquemática os principais momentos de transição na nossa linhagem. Este artigo apresenta uma primeira parte que define as bases teóricas utilizadas, seguida de uma seção com conceitos básicos para a definição de nossa linhagem e a seguir discute cada uma das três transições aqui propostas. Por fim, e não menos importante, este texto presta uma homenagem à obra de Paulo Abrantes, discutindo em sua parte final algumas ideias levantadas por ele à luz desse texto.
Teoria da evolução e evolução humana

A evolução biológica constitui a base teórica deste artigo. Embora a teoria contemporânea de evolução tenha como o seu maior expoente o naturalista Charles Darwin, ela inclui um corpo teórico que tem sido construído desde o século XVIII e que continua em transformação. A teoria sintética de evolução, por exemplo, foi formulada entre as décadas de 1930 e 1950, e teve um papel crucial na junção das ideias de seleção natural de Darwin e dos princípios da genética Mendeliana. A partir da teoria sintética da evolução considerase que evolução biológica é constituída por quatro forças: mutação, deriva genética, fluxo gênico e seleção natural (Ridley, 2004; Meyer e El-Hani, 2005). Ao longo do século XX, as discussões em teoria evolutiva abordaram controvérsias sobre o adaptacionismo, os níveis de seleção natural, o ritmo da evolução e a biologia do desenvolvimento, formando um corpo teórico complexo e robusto (Abrantes, 2011). Recentemente, modelos de evolução biológica que destacam múltiplas heranças têm ganhado força, sendo que a herança biológica clássica é acompanhada da herança epigenética, comportamental e simbólica (Jablonka e Lamb, 2005). 
A evolução humana é apenas um caso dentre a enorme diversidade de histórias evolutivas dos organismos do planeta. Por outro lado, ela é um ótimo estudo de caso para o entendimento das relações gerais entre herança biológica e cultural, uma vez que ambos os processos são atuantes na nossa trajetória evolutiva ( $\mathrm{Da}-$ Gloria, 2009). Um outro motivo para a relevância da evolução humana é o próprio entendimento do comportamento humano, que é crucial para as ciências sociais e da saúde. Ao contrário do que é postulado por alguns pensadores de que os seres humanos funcionam por princípios especiais, a teoria evolutiva tem mostrado que todos os organismos vivos são conectados pela ancestralidade comum, aproximando os seres humanos do restante dos organismos vivos. Esse ponto tem sido extensamente desenvolvido desde o século XIX, quando Huxley (1863) e Darwin (1871) abordaram a conexão dos humanos com outros animais, mostrando as semelhanças e diferenças com outras espécies, especialmente com primatas. Ao contrário do que se postulava entre os Darwinistas sociais do século XIX, a teoria biológica de evolução não defende uma linearidade progressiva das espécies e não hierarquiza os organismos em termos de complexidade biológica (Freeman,
1974). Esses aspectos são muito relevantes para a evolução humana na medida que nossa espécie não está no ápice de uma hierarquia e seus traços não devem ser entendidos como teleológicos, ou seja, com uma finalidade ou um objetivo.

A partir dessas considerações, este texto busca delinear os traços que nos distinguem como linhagem, enfatizando aspectos biológicos e culturais, e utilizando a teoria biológica de evolução como base teórica. Nesse ponto, o texto aborda as evidências empíricas recentes da evolução humana ao mesmo tempo que as explica usando o conceito de causas últimas. Por esse conceito, procurase a razão evolutiva para a existência de um determinado traço (Mayr, 1961). Além disso, embora reconhecido a diversidade de forças evolutivas atuantes para a geração do organismo biológico, este texto enfatiza o conceito de seleção natural e adaptação biológica, pois eles parecem ser os conceitos mais adequados para explicar a origem dos traços aqui discutidos.

\section{Estabelecendo conceitos básicos: tempo, espaço e classificação}

$\mathrm{O}$ primeiro passo para um entendimento sólido da evolução humana é a definição de conceitos básicos de tempo, espaço e classificação. A relação evolutiva pró- 
xima entre os grandes símios africanos e os humanos têm sido observada tanto no nível comportamental como anatômico desde o século XIX (Huxley, 1863; Darwin, 1871). No entanto, ao longo do século XX, diversos autores defenderam que nosso parente vivo mais próximo poderia ser o gibão (Hylobates), o orangotango (Pongo), o gorila (Gorilla) ou o chimpanzé (Pan). A evidência conclusiva desse debate só veio com o advento das técnicas de biologia molecular na segunda metade do século XX. O trabalho clássico de Wilson e Sarich (1969) apontou para a semelhança molecular entre grandes símios africanos e humanos, porém não foi conclusiva quanto a qual deles seria o nosso parente evolutivo mais próximo. Nesse aspecto, o avanço técnico na extração e sequenciamento de DNA foi decisivo para a resolução desse debate (Harris, 2015). Usando 14 fragmentos independentes de DNA, Ruvuolo (1997) confirmou que somos mais próximos dos chimpanzés, depois dos gorilas e por fim dos orangotangos, confirmando de maneira sólida a nossa conexão com os grandes símios africanos. Essa ordem de parentesco foi confirmada através de sequências completas de alta cobertura do genoma de vários indivíduos dessas espécies (PradoMartinez et al., 2013). É importante destacar que o sequencia- mento completo do genoma de um indivíduo inclui cerca de três bilhões de pares de bases, o que garante uma enorme quantidade de informação comparativa para traçar linhas de parentesco biológico.

A partir da confirmação do grau de similaridade biológica entre os grandes símios e os humanos, é possível trabalhar com uma taxonômica biológica dessas espécies, utilizando-se de uma classificação baseada nos trabalhos de Carolus Linnaeus no século XVIII. Seguindo Wood e Harrison (2011), hominínios são todos os indivíduos da linhagem humana do momento que viveu o último ancestral comum com os chimpanzés (grupo este que inclui os bonobos), até os humanos modernos. Os hominínios são classificados no nível de tribo, que é o nível taxonômico entre família e gênero. A linhagem dos chimpanzés, por sua vez, está classificada na tribo panini. Já a superfamília dos hominóides inclui humanos, chimpanzés, gorilas, orangotangos e gibões e todas as suas linhagens fósseis. Essa classificação é importante, pois reflete uma relação biológica próxima com os chimpanzés, ou seja, no nível de tribo, além de fornecer uma denominação formal, que será usada por todo esse artigo, para se referir a nossa linhagem, a dizer, a linhagem hominínia.

Uma vez definidas as linhagens 
hominínia e panínia, é preciso estabelecer quando o ancestral comum dessas duas linhagens viveu. Os dados genéticos são novamente decisivos na resolução dessa questão, pois eles permitem, usando o genoma de espécies viventes, a obtenção do tempo de coalescência dessas espécies, ou seja, o momento que viveu o ancestral comum das espécies em questão. Para o cálculo da coalescência é necessário estabelecer uma taxa de mutação, que pode ser obtida usando outros grupos de animais que possuem registro fóssil bem estabelecido (Harris, 2015). Na prática, esses cálculos são bastante imprecisos, fornecendo um intervalo de idade amplo, além de taxas de mutação bastante variáveis (Scally e Durbin, 2012). No caso das linhagens panínia e hominínia, dados genéticos de múltiplos estudos têm chegado a um tempo de coalescência entre 6 e 4 MAA (milhões de anos atrás), além de sugerirem que populações ancestrais dessas linhagens trocaram genes por um período de cerca de 4 milhões de anos antes de se separarem completamente entre 6 e 4 MAA (Patterson et al., 2006). Essas datas, porém, contradizem possíveis fósseis da linhagem hominínia datados de antes de 6 MAA (ver abaixo), e nos levam a ver essas datas com algumas ressalvas. De fato, estimativas considerando tempos de geração mais longos dos grandes símios obtiveram datas entre 8 e 7 MAA para a separação entre as linhagens (Langergraber et al., 2012). Embora apresentando uma alta imprecisão, as análises de coalescência são um importante guia para a identificação do momento de início da linhagem hominínia, que parece ter ocorrido entre 8 e 4 MAA.

A última questão básica a ser respondida é onde ocorreu o surgimento da linhagem hominínia. Com a definição dos grandes símios africanos (gorilas e chimpanzés) como os mais próximos biologicamente dos humanos, a hipótese de surgimento da linhagem hominínia na África ganha força. Outra evidência que aponta fortemente para a África são os fósseis classificados como hominínios. Entre 7 e 2 MAA, todos os fósseis da nossa linhagem são encontrados naquele continente, parecendo sugerir que o início da nossa linhagem realmente ocorreu na África. No entanto, o registro fóssil na África entre 13 e 7 MAA é muito pobre, consistindo apenas de poucos fragmentos fósseis de três gêneros: Nakalipithecus (Kunimatsu et al., 2016), Samburupithecus (Ishida e Pickford, 1997), e Chororapithecus (Suwa et al., 2007), além de alguns fragmentos de dentes encontrados em Ngorora, Quênia (Pickford e Senut, 2005) e Ni- 
ger (Pickford et al., 2008). Esse registro fóssil tem aumentado nos últimos 20 anos, mas ainda assim não é forte o suficiente para traçar uma conexão entre os hominóides fósseis viventes antes e depois de 7 MAA. Essa escassez de fósseis na África é contrastada com uma abundância de fósseis na Eurásia, incluindo gêneros como Dryopithecus, Ouranopithecus e Ankarapithecus (Begun, 2016). Essa evidência fóssil tem levado alguns autores a postularem que a nossa linhagem é oriunda da Europa e só depois migrou para a África (Begun et al., 2012). Fuss et al. (2017), por exemplo, baseados em características dentais de Graecopithecus datados de 7,2 MAA e encontrados na Grécia e Bulgária, propõem que esse gênero apresenta traços de anatomia dental de um ancestral dos hominínios, embora haja poucos fragmentos fósseis desse gênero. De fato, a questão do local de origem da nossa linhagem ainda está em aberto. Embora haja muito mais fósseis de hominóides na Europa do que na África entre 13 e 7 MAA, é ainda razoável pensar na África como o local de origem dos símios africanos, e que o registro fóssil africano ainda não tenha sido devidamente explorado.

Primeira transição: bipedia e diminuição dos caninos
É difícil imaginar como seria a morfologia do ancestral comum dos chimpanzés e humanos. Podese pensar nesse ancestral como o intermediário dos dois grupos viventes, ou, como usualmente ocorre, imaginar o ancestral comum como um organismo similar a um chimpanzé, uma vez que se assume que os humanos se distanciaram mais em relação à morfologia e ao comportamento dos grandes símios. Uma terceira possibilidade é utilizar os fósseis que são seguramente posicionados em nossa linhagem como base para a interpretação do ancestral comum. White et al. (2015), por exemplo, baseando-se em fósseis hominínios de 4,4 MAA, argumentaram que o ancestral comum dos hominínios e panínios era diferente de ambos os grupos vivos, parecendo mais com macacos do Velho Mundo, que se locomovem de forma quadrúpede sobre os galhos, com frequente postura pronograda. O uso dos fósseis para inferir a característica do ancestral comum é válida, porém quanto mais próximo se chega do ancestral comum mais difícil é reconhecer se ele pertence à uma linhagem específica. De fato, o debate sobre a morfologia desse ancestral ainda não está resolvida, e outros pesquisadores acreditam que o ancestral comum teve uma locomoção suspensória e uma postura ortograda, 
assim como os grandes símios viventes (Begun, 2016).

Nesse ponto, a escavação de fósseis temporalmente e geograficamente próximos de onde se imagina que o ancestral comum viveu é fundamental para a elucidação de sua morfologia. Nos últimos 20 anos, fósseis que datam entre 7 e 5 MAA foram descobertos na África, dos quais se destacam três espécies: Sahelantropus tchadensis encontrada no Chade e datada entre 7 e 6 MAA (Brunet et al., 2002, 2005), Orrorin tugenensis encontrada no Quênia e datada em 6 MAA (Senut et al., 2001) e Ardipithecus kadabba encontrada na Etiópia e datada entre 5,8 e 5,2 MAA (Haile-Selassie, 2001, HaileSelassie et al., 2004). O S. tchadensis é representado por um crânio bastante completo, com volume craniano de $365 \mathrm{~cm}^{3}$, similar ao volume do crânio de um grande símio. Esse crânio apresenta um forame magno, que é a abertura na base do crânio que liga a medula espinhal com o cérebro, com posição anterior, o que foi confirmado pelo uso de uma reconstrução virtual que corrige distorções tafonômicas (Zollinkofer et al., 2005). De fato, a posição anterior do forame magno no crânio de mamíferos é um bom preditor de locomoção bípede (Russo e Kirk, 2017), uma vez que a posição do crânio é superior ao corpo nesse tipo de loco- moção, transformando esse espécime no primeiro fóssil com evidência de bipedia na nossa linhagem. Além disso, o fóssil apresenta traços dentais que são compatíveis com características típicas de nossa linhagem, a dizer, um canino relativamente pequeno e dentes com esmalte mais espesso que os de chimpanzés e gorilas. Embora alguns pesquisadores ainda questionem a inclusão desse fóssil na linhagem hominínia (Wolpoff et al., 2006), sugerindo que o indivíduo pudesse ser uma fêmea da linhagem do gorila, as evidências de bipedia são um forte indício de que esse espécime é o hominínio mais antigo encontrado até o momento.

Os fósseis associados ao $\mathrm{O}$. $t u$ genensis consistem de dentes, falanges, úmero e fêmur. A característica anatômica que mais chama a atenção é a porção proximal do fêmur com características que indicam bipedia, tais como o pescoço do fêmur longo e achatado, a presença do sulco para o músculo obturador externo (Pickford et al., 2002) e o padrão de espessura do córtex do pescoço do fêmur (Galik et al., 2004). Outros pesquisadores concluíram que essa morfologia do fêmur proximal é intermediária entre os fósseis de hominoides do Mioceno e os fósseis de australopitecíneos, que são seguramente posicionados na linhagem hominínia (Richmond e Jun- 
gers, 2008; Bleuze, 2012; Almecija et al., 2013). Por outro lado, as falanges da mão são longas e curvas, similares às falanges de grandes símios com locomoção suspensória, indicando que essa espécie ainda mantinha um comportamento arbóreo. Já os caninos são de tamanho intermediário, se assemelhando ao de fêmeas de chimpanzés, embora os dentes molares têm esmalte espesso, como a maioria dos dentes da nossa linhagem.

Os fósseis de Ar. kadabba constituem-se de dentes, fragmentos de clavícula, braço, mão e pé. O que mais chamou atenção nesses fósseis foi uma quarta falange proximal do pé bastante larga e robusta, encontrada em estratos de 5,2 MAA, o que parece indicar o uso do pé para uma locomoção bípede (Haile-Selassie, 2001). Porém, essa é uma evidência muito frágil para comprovar com segurança a bipedia dessa espécie. Assim como O. tugenensis, os dentes caninos são intermediários entre humanos e chimpanzés, com canino e primeiro pré-molar inferior fazendo parte de um complexo afiador, que faz com que o desgaste do canino seja lateral e não na ponta do dente como ocorre em humanos (Haile-Selassie et al., 2004). Por outro lado, os dentes molares têm esmalte espesso, que é um traço típico da linhagem hominínia.
Um achado mais recente é a descoberta da espécie Ardipithecus ramidus. Esses fósseis tiveram um impacto muito significativo no campo da evolução humana, já que são caracterizados por dezenas de indivíduos datados de 4,4 MAA, incluindo um indivíduo bastante completo do sexo feminino, que foi batizado de Ardi (White et al., 2009). Com um material fóssil muito mais completo que os fósseis mais antigos, foi possível observar diversos traços típicos de bipedia, tais como o forame magno mais anterior (Suwa et al., 2009a) e a anatomia da bacia, do joelho e do tornozelo indicando uma postura bípede (Lovejoy et al., 2009a). Por outro lado, a anatomia desse indivíduo não era a mesma da anatomia bípede dos humanos modernos, pois eles apresentavam uma bacia com ísquio semelhante aos de grandes símios, ou seja, ancorando uma musculatura posterior da coxa forte e apropriada para trepar em árvores. Além disso, os braços são tão compridos quanto as pernas, que é diferente de humanos modernos que possuem pernas relativamente mais longas. $\mathrm{O}$ dedão do pé era opositor como em grandes símios e a capacidade craniana ainda era pequena, semelhante à de um chimpanzé. A anatomia da mão também era intermediária entre humanos e chimpanzés, apresentando metacarpos 
e falanges relativamente curtos e dedão da mão proporcionalmente mais longo, diferente dos chimpanzés, porém com falanges da mão curvas, se aproximando da anatomia de um primata arbóreo (Lovejoy et al., 2009b). Esse mosaico de características mostra que a anatomia bípede surgiu de forma gradual, e que indivíduos da espécie $A r$. ramidus ainda apresentavam uma locomoção que conciliava hábitos arbóreos e terrestres. Quanto aos dentes, os molares apresentavam esmalte fino, tal como em gorilas e chimpanzés, mas, diferentes destes últimos, os caninos eram menores, sem dimorfismo sexual, ou seja, machos e fêmeas tinham caninos de igual tamanho, e com o complexo afiador bem pouco desenvolvido (Suwa et al., 2009b).

Uma vez revisado a evidência fóssil dos primeiros milhões de anos de nossa linhagem, é crucial entender em que ambiente eles viviam. A bipedia é entendida aqui como uma forma de locomoção que está associada a um conjunto de traços anatômicos que exercem uma função em determinado ambiente (Lovejoy, 2005a,b, 2007). A reconstituição do paleoambiente utiliza-se de múltiplas evidências que incluem desde macrorestos botânicos e faunísticos até marcadores químicos e moleculares do solo. A região de Toros-
Menalla no Chade, onde foi encontrado o S. tchadenseis, parece ter sido constituída por um mosaico de áreas abertas, com pastagens secas e úmidas, e por habitats arborizados com presença de corpos de água (Le Fur et al., 2014). Já o O. tugenensis foi encontrado na formação Lukeino, Quênia, onde as reconstituições paleoambientais indicaram também um mosaico de áreas abertas e florestadas, próximas a fontes de água (Pickford e Senut, 2001; Bamford et al. 2013; Roche et al., 2013). Recentemente, utilizando-se de marcadores geoquímicos do solo, Dericquebourg et al. (2015) concluíram que a região continha uma densa área florestada ao redor de um lago, enfatizando que o local era bastante úmido naquele período. Já os fósseis de Ar. ramidus foram encontrados em Aramis, Etiópia, cuja reconstrução paleoambiental indicou um ambiente de bosques e florestas (WoldeGabriel et al., 2009). Por outro lado, reconstruções ambientais utilizandose de marcadores moleculares do solo têm mostrado que a proporção de árvores da África tem diminuído desde 6 MAA (Cerling et al., 2011) e, especificamente, que o Ar. ramidus viveu na verdade em um ambiente de mosaico de áreas abertas e fechadas próximo a fontes de água com mata ciliar (Gani e Gani, 2011). Em síntese, 
houve um melhoramento significativo das reconstruções ambientais na África nas últimas décadas, mostrando uma tendência ao ressecamento a partir de 6 MAA. Por outro lado, ainda existe um debate sobre qual era o microambiente em que viveram esses primeiros hominínios, se mais aberto ou mais sombreado. É bem possível que eles tenham circundado em áreas de mosaico de ambientes abertos e florestados próximos a corpos de água.

O próximo grande grupo de fóssseis são os australopitecíneos, que incluem uma diversidade de formas pertencentes a três gêneros, a dizer: Paranthropus, Australopitethecus e Kenyanthropus, e que viveram entre 4,2 MAA e 1,2 MAA. No que diz respeito à bipedia, esse período é marcado pela consolidação da anatomia bípede, muito próxima daquela que encontramos em humanos modernos. Uma mudança significativa que ocorreu nos fósseis desse período foi relacionada à anatomia do pé, e pode ser confirmada pela preservação de pegadas na região de Laetoli, Tanzânia, há 3,6 MAA. Essas pegadas mostram que o dedão do pé dos australopitecíneos era paralelo ao restante dos dedos, funcionando então como uma alavanca para um caminhar bípede mais eficiente (Schmid, 2004). A anatomia de um quarto metatarso do pé encontrado em camadas de 3,2 MAA também sugere uma melhor eficiência na bipedia, uma vez que ele indica a presença de arcos longitudinal e transversal no pé de australopitecíneos (Ward et al., 2011). Reconstruções de bacias de Australopithecus africanus utilizando-se de tomografia computadorizada, confirmaram que os ossos do pélvis apresentavam uma morfologia tipicamente bípede. Por outro lado, essa anatomia também mostrou um osso do íleo bastante largo, sugerindo assim uma variação na mecânica de caminhada dessa espécie em relação aos humanos modernos, que apresentam bacia mais estreita (Berges e Goularas, 2010; Claxton et al., 2016). A anatomia pós-craniana dos australopitecíneos também sugere algumas diferenças na mecânica de caminhada em relação aos humanos modernos. Os Australopithecus afarensis, por exemplo, apresentavam tórax em formato de funil, os braços relativamente mais longos em relação às pernas e falanges da mão curvas, indicando que eles ainda conciliavam uma locomoção arbórea e terrestre (Kimbel e Delezene, 2009). Mostrando a diversidade de formas dos australopitecíneos, DeSilva et al. (2013) estudaram a anatomia dos membros inferiores do Australopithecus sediba, encontrados no sul da África por volta de 2 MAA, e concluíram que a pisada deles era hiperpronada, com 
os pés sendo apoiados de fora para dentro ao mesmo tempo que giravam a perna no momento da passada. Essa mobilidade extra do tornozelo poderia ser uma forma de conciliar locomoção arbórea e terrestre, e que era diferente daquela adotada por outros australopitecíneos. No que concerne à dentição, os caninos de australopitecíneos eram marcados pelo tamanho reduzido e pelo baixo dimorfismo sexual, traços estes que são mantidos por toda a linhagem hominínia até os humanos modernos. O significado dessa característica será explorado mais à frente nesta seção.

A última etapa na transição para uma morfologia bípede moderna aconteceu com o surgimento da espécie Homo erectus há cerca de 1,9 MAA na África. No que concerne ao esqueleto pós-craniano, essa espécie é marcada por apresentar massa corpórea maior que os australopitecíneos, girando entre 48 a $63 \mathrm{~kg}$ e com altura média de $1,7 \mathrm{~m}$, além de ter pernas relativamente mais compridas que os braços, caixa torácica cilíndrica e falanges de mão retas, apresentando uma anatomia correspondente a uma locomoção exclusivamente terrestre. Pegadas preservadas em Illeret, Quênia, e datadas em 1,5 MAA, confirmaram o andar bípede moderno dessa espécie, tanto no que diz respeito às passadas longas como também à maior massa corpórea (Dingwall et al., 2013). Há também diversas evidências anatômicas que indicam que o $H$. erectus foi selecionado também para realizar corridas de longa duração, tais como o tórax em formato de barril e a morfologia do osso calcâneo do pé (Bramble e Lieberman, 2004). Mudança na anatomia dos ombros, tais como posicionamento lateral da escápula e ombros mais largos, indica que os H. erectus já apresentavam condições de realizar arremessos de objetos, o que pode ter favorecido atividades relacionadas à sobrevivência em ambientes abertos (Roach et al., 2013). De fato, acredita-se que a locomoção bípede exclusiva só ocorreu quando os hominínios passaram a ocupar de maneira significativa ambientes abertos de savana.

Após essa breve revisão sobre a evidência fóssil e ambiental dos primeiros hominínios, é crucial entender quais são as hipóteses evolutivas relacionadas à aquisição da bipedia e à diminuição dos caninos. No que concerne à bipedia, os dados empíricos levantados aqui nos levam a uma série de implicações. Primeiro, a transição de uma locomoção arbórea para uma locomoção exclusivamente terrestre foi gradual, iniciando-se no começo de nossa linhagem há $7 \mathrm{MAA}$ e completada somente com o surgimento do $H$. erectus há cerca de 
2 MAA. Segundo, houve um processo gradual de diminuição de cobertura florestal na África a partir de 6 MAA, com uma diminuição ainda maior depois de 2,5 MAA, cuja significância provavelmente influiu no processo de aquisição da bipedia. Terceiro, as razões evolutivas últimas para a aquisição da bipedia podem ter variado ao longo desses primeiros milhões de anos de nossa linhagem, permitindo que múltiplas forças seletivas tenham atuado nesse processo. De fato, ainda não temos evidências empíricas definitivas para explicar evolutivamente o surgimento da bipedia, embora haja muitas hipóteses candidatas. Nos parágrafos abaixo irei discutir quatro conjuntos de hipóteses evolutivas para explicar a bipedia.

O primeiro conjunto de hipóteses evolutivas para explicar a bipedia se refere a uma transição postural e locomotora que ocorreu ainda em meio arbóreo. Esse conjunto de hipóteses está ligado à observação do comportamento dos grandes símios em ambiente natural. Observações de chimpanzés em campo constataram que eles ficam em posição ereta sobre galhos mais grossos, e utilizam uma das mãos para coletar frutas (Stanford, 2006), sendo que em alguns locais foi observada também a coleta de frutos em arbustos baixos com os dois pés apoiados no chão (Hunt,
1996). Essas observações levaram os pesquisadores a formularem a hipótese do forrageio arbóreo, que explica o início da bipedia como uma adaptação postural, e não locomotora. Outros pesquisadores, ao observarem orangotangos em ambiente natural, constataram que em certas ocasiões eles se locomovem de forma bípede sobre galhos grossos de árvore, usando algumas vezes uma mão para segurar galhos a fim de não perder o equilíbrio (Thorpe et al., 2007). Nesse caso, a bipedia seria uma forma de locomoção no alto das árvores. Em ambos os casos, a origem da bipedia estaria relacionada a uma vida arbórea, inclusive podendo ter sido uma adaptação comportamental do ancestral comum dos grandes símios e dos humanos, e que de alguma forma aumentou de importância em condições ecológicas específicas na linhagem hominínia. Um dos dados empíricos que sustentam essa hipótese é o uso de uma técnica de extração de isótopos estáveis de carbono do esmalte dentário de fósseis, detectando se o indivíduo se alimentou de fontes de carbono de lugares sombreados (plantas C3 típicas de matas e bosques) ou de áreas abertas (plantas C4 típicas de ambientes abertos de savana). Esses dados mostraram que a base alimentar do Ar. ramidus há 4,4 MAA ainda era muito dependente de ambientes sombre- 
ados, assim como ocorre em chimpanzés (White et al., 2009).

O segundo conjunto de hipóteses para explicar bipedia está relacionado à liberação das mãos para a realização de múltiplas tarefas. Carvalho et al. (2012) testaram essa hipótese, e confirmaram que na presença de recursos raros e de ocorrência imprevisível, chimpanzés tendem a usar a locomoção bípede para transportar itens alimentares ou ferramentas de pedra para locais protegidos. Dentro dessa mesma linha, Lovejoy $(1981,2009)$ defende que a bipedia surgiu devido à interação de fatores anatômicos, sociais e reprodutivos ligados à diminuição da agressividade entre machos (inferidos a partir de caninos pequenos e com baixo dimorfismo sexual; ver discussão mais abaixo), ou seja, em um modelo social de formação de núcleos familiares estáveis. As mãos, então liberadas pela bipedia, serviriam para carregar comida em um contexto social de formação de casais de longa duração, com aumento de cuidado parental e ovulação silenciosa das fêmeas, fazendo com que os indivíduos trouxessem o alimento para o seu núcleo familiar. A crítica a esse modelo é baseada na falta de evidências fósseis de mudanças do padrão de história de vida (e.g., prolongamento do crescimento e desenvolvimento) e de formação de núcleos familiares nos primeiros hominínios, que só começaram a alterar a sua história de vida mais tardiamente com o surgimento do gênero Homo (DaGloria, 2014). Outra possibilidade é a liberação das mãos para carregar bebês, pois após a perda de pelos nos hominínios, as crianças não poderiam ficar mais penduradas na mãe, como ocorre em chimpanzés (Amaral, 1996, 2013). A crítica a esse modelo é de que a perda de pelos parece ter ocorrido somente há $2 \mathrm{MAA}$, quando os hominínios começaram a viver de forma definitiva nas savanas de baixa altitude (Dávid-Barrett e Dunbar, 2016). Evidências genéticas para a perda de pelos não são definitivas para esclarecer essa questão, pois fornecem datas para a fixação de genes da pele escura em 1,2 MAA na nossa linhagem (Rogers et al., 2004) e datas de 4 a 3 MAA utilizando-se de estudos de piolhos da região pubiana e da cabeça em humanos (Reed et al., 2007). Por fim, a liberação das mãos para fazer instrumentos é também uma possibilidade lógica para explicar a bipedia. Porém, a evidência de ferramentas de pedra no registro fóssil só ocorre a partir de 3,3 MAA (ver discussão na próxima seção). Em síntese, as hipóteses que postulam que a bipedia surgiu para a liberação das mãos não apresentam ainda evi- 
dências sólidas para explicar o início dessa transição. Por outro lado, em momentos mais tardios, o uso das mãos pode ter sido uma força evolutiva importante para o surgimento da bipedia exclusiva, assim como a encontramos em humanos modernos.

O terceiro conjunto de hipóteses está intimamente ligado à vida em ambientes abertos de savana, e é chamado de hipóteses termodinâmicas. Em ambientes abertos, a bipedia diminui a exposição do corpo ao sol e aumenta a exposição ao vento, evitando superaquecimento do corpo. Associada à bipedia, a perda de pelos teria surgido nesse contexto junto com as glândulas sudoríparas, que ao produzirem o suor, ajudariam na liberação de calor do corpo (Wheeler, 1984, 1991, 1993). Ruxton e Wilkinson (2011) mostram que a corrida de longa duração só é possível em ambientes abertos, desde que os hominínios sejam dotados de locomoção exclusivamente bípede, ausência de pelos e presença de glândulas sudoríparas. Esse pacote de mudanças parece ter sido um fator seletivo importante na ocupação exclusiva de ambientes abertos de baixa altitude há 2 MAA (David-Barret e Dunbar, 2016), e está associado a mudanças anatômicas que levaram ao surgimento da bipedia moderna em $H$. erectus. É possível que a importân- cia da termodinâmica para a bipedia possa ter começado a atuar alguns milhões de anos antes, uma vez que evidências de isótopos estáveis de carbono de dentes de australopitecíneos, tais como os de $A u$. Afarensis que apareceram há cerca de 3,9 MAA, sugerem que eles se alimentavam de cerca de $50 \%$ de itens oriundos de locais abertos, ou seja, com sinal isotópico de plantas C4 (Wynn et al., 2013; Sponheimer et al., 2013). Essa transição para locais abertos ocorrida a partir de 4 MAA pode ter gerado uma pressão seletiva em direção à bipedia moderna devido a fatores termodinâmicos. Por outro lado, essas mudanças parecem não poder ser usadas para explicar os primeiros passos da transição para a bipedia há 7 MAA.

Por fim, o último conjunto de hipóteses para explicar a bipedia refere-se à questão energética. Devido à anatomia e à mecânica da locomoção, o caminhar bípede em humanos economiza $75 \%$ de energia em relação ao andar bípede ou quadrúpede do chimpanzé. Por esse prisma, a bipedia teria sido selecionada para economizar energia em indivíduos que realizassem longas caminhadas no solo (Sockol et al., 2007; Pontzer et al., 2009, 2014; O’Neil et al., 2015). Os autores que defendem a hipótese energética acreditam que espécies com anatomia parcialmente bípede de- 
vem ter apresentado alguma economia de energia na locomoção em ambientes terrestres. O grande desafio desse modelo é conseguir estimar a magnitude da economia de energia dessas espécies extintas, tais como os Ar. ramidus, em situações de caminhadas de longas distâncias.

Junto com a bipedia, a outra característica definidora dessa primeira transição na linhagem hominínia é a diminuição dos caninos. A evidência fóssil indica que os caninos diminuíram desde o começo da nossa linhagem, como observado no espécime de $S$. tchadensis há 7 MAA. Porém, a inferência de dimorfismo sexual dos caninos só é possível com a presença de muitos indivíduos de ambos os sexos, e esse baixo dimorfismo só é confirmado a partir de Ar. ramidus há 4,4 MAA. Há duas hipóteses principais para explicar a diminuição dos caninos e seu baixo dimorfismo sexual. A primeira delas é a correlação em primatas de dimorfismo sexual tanto dos caninos como da massa corpórea com grau de agressividade entre machos (Plavcan, 2012). Notem que os primatas raramente usam seus caninos para caçar, usandoos na realidade para disputas entre machos para o acesso às fêmeas ou para proteção de territórios. Da mesma forma, machos maiores tendem a ser mais efici- entes em conflitos intraespecíficos. Por essa hipótese, a diminuição do dimorfismo sexual e do tamanho absolutos dos caninos está ligada à diminuição da agressividade dos machos em nossa linhagem. Uma segunda hipótese para explicar a diminuição do canino é relacionada à alimentação. Primeiro, alguns autores defendem que o canino desempenha uma função importante na obtenção de alimentos, e isso seria prejudicado pelo tamanho excessivo dos caninos (Greenfield, 1998). Segundo, o tamanho do canino demanda uma alta capacidade de abertura da boca para que o indivíduo possa usá-lo efetivamente. A abertura da boca também está ligada ao posicionamento dos músculos da mastigação, pois quando eles estão mais anteriores na mandíbula, há maior força na mastigação, ao mesmo tempo que há menor abertura da boca (Haylander, 2013). Seguindo esse raciocínio, a seleção natural poderia favorecer caninos menores em espécies que não conseguiriam ter uma grande abertura da boca, pois precisariam de maior força muscular para a mastigação de alimentos duros ou fibrosos.

A evidência fóssil de Ar. ramidus é caracterizada pelo baixo dimorfismo sexual tanto da massa corpórea como dos caninos, fortalecendo a hipótese de diminuição de agressividade entre machos, e de 
maneira indireta podendo indicar uma diferença de organização social dos primeiros hominínios em relação aos símios africanos. Por outro lado, fósseis de australopitecíneos são caracterizados por caninos pequenos e com baixo dimorfismo sexual, assim como os Ar. ramidus, porém eles apresentam alto dimorfismo sexual de massa corpórea (Plavcan et al., 2005). Os dados de massa corpórea e caninos apontam para direções diferentes em relação à agressividade dos machos nesse grupo. Contudo, há uma clara mudança de dieta em australopitecíneos, com presença de esmalte dentário espesso e consumo de alimentos de regiões abertas, o que representa uma tendência para uma alimentação mais dura e fibrosa, ao contrário do que é observado em chimpanzés. Esses dados reforçam a hipótese de que a dieta pode ter sido um fator importante na manutenção de caninos pequenos entre australopitecíneos, mesmo que a agressividade entre machos tenha aumentado nesse período. Em síntese, as duas hipóteses levantadas para explicar diminuição dos caninos em hominínios podem ter agido em momentos diferentes da nossa linhagem, sendo que ambas as forças ocasionaram diminuição dos caninos e de seu dimorfismo sexual desde o começo de nossa linhagem.

\section{Segunda transição: ferramentas, expansão do cérebro e diminuição dental}

A segunda grande transição na nossa linhagem é o aparecimento do gênero Homo. Essa classificação taxonômica é um tanto quanto arbitrária, sendo historicamente relacionada à maneira que se define nossos traços distintos como gênero. Um primeiro critério usado para a inclusão de uma espécie no gênero Homo é o tamanho do cérebro. Arthur Keith estabeleceu o valor mínimo de $750 \mathrm{~cm}^{3}$ para o tamanho da caixa craniana de um indivíduo do nosso gênero (Keith, 1948). Já Louis Leakey, ao nomear um crânio de menos de 750 $\mathrm{cm}^{3}$ como Homo habilis, substituiu o cérebro pelo uso de instrumentos como traço definidor de nosso gênero (Leakey et al., 1964). Por fim, uma terceira abordagem é a definição de nosso gênero através da morfologia dentária, que é caracterizada, entre outros traços, por uma tendência à redução dental. Nessa linha de raciocínio, o fóssil mais antigo do gênero Homo é uma mandíbula fragmentada com dentes encontrada na Etiópia e datada em 2,8 MAA (Villmoare et al., 2015). Nessa seção, discutiremos o aparecimento desses três traços na nossa linhagem: ferramentas, expansão do cérebro e diminuição dental. 
O uso de instrumentos não é de maneira alguma exclusividade de humanos. Os grandes símios utilizam-se de diversos tipos de instrumentos, sendo que os chimpanzés são aqueles que apresentam os instrumentos mais elaborados (Boesch et al., 2009). Em um levantamento do uso de instrumentos em condições naturais e com o auxílio de estimativas genéticas de demografia, Haslam (2014) concluiu que o nosso ancestral comum com os chimpanzés usou galhos e folhas como instrumentos, mas provavelmente não fabricou instrumentos de pedra. Instrumentos de pedra usados para quebrar coquinhos, por exemplo, são restritos a um grupo específico de chimpanzés do oeste da África, e parecem ter surgido recentemente de forma independente dos instrumentos fabricados pelos hominínios. Outros primatas, como os macacos pregos brasileiros, lascam pedras (Proffitt et al., 2016), porém esses instrumentos ainda não foram encontrados em depósitos mais antigos que 700 anos antes do presente (Haslam et al., 2016). O que distingue nossa linhagem de outros primatas é o uso consistente de rochas para a produção de instrumentos, que apresentam um padrão de modificação caracterizado pelos pesquisadores como uma indústria de pedra e são identificáveis em contexto arqueo- lógico antigo.

A primeira indústria de pedra encontrada no contexto da evolução humana foi denominada Lomekianense, encontrada a oeste do lago Turkana no Quênia e datada em 3,3 MAA. Ela é composta por lascas relativamente grandes retiradas de seixos e blocos de pedra (Harmand et al., 2015). Esses primeiros instrumentos de pedra são bastante relevantes para a nossa discussão por dois motivos. Primeiro, eles ocorrem muitos milhões de anos depois do surgimento dos primeiros bípedes na nossa linhagem. Segundo, eles ocorrem antes da expansão do cérebro e diminuição dental, que ocorre mais de 1 milhão de anos depois. Esses achados, no entanto, não implicam que o uso de instrumentos não seja mais antigo que essa data, já que se pode imaginar o uso de mãos livres para fabricar instrumentos menos visíveis arqueologicamente. Por outro lado, é seguro afirmar que o gênero Homo não foi o primeiro a usar instrumentos de pedra, e que australopitecíneos, com tamanho do cérebro e histórias de vida similares aos chimpanzés, foram os primeiros a fabricar indústrias de pedra reconhecíveis arqueologicamente. A função desses primeiros instrumentos ainda não foi devidamente investigada, porém é possível que ela tenha sido usada 
para múltiplos propósitos. Evi- Sua principal característica é a predência de marca de corte em um sença de um instrumento chamado osso de fauna em Dikika, Etió- machado de mão. Esse instrupia, datado de 3,4 MAA, sugere mento tem o formato de gota e era que os fabricantes dos instrumentos poderiam ter usando as lascas para cortar animais (McPherron et al., 2010). Contudo, como veremos a seguir, o consumo significante de carne só apresenta evidências sólidas mais de um milhão de anos depois. Pode-se postular que esses primeiros instrumentos tiveram alguma importância para a vida dos australopitecíneos em ambientes de mosaico de áreas abertas e sombreadas, e consequentemente para o início do consumo de alimentos em áreas de savana aberta.

Após esses primeiros achados, a próxima indústria produzida na nossa linhagem é a indústria Olduvaiense, com sua primeira ocorrência em Gona, Etiópia, há 2,6 MAA (Semaw et al., 1997). A indústria Olduvaiense é composta principalmente por talhadores (choppers) e lascas simples retiradas de blocos de pedra ou seixos rolados, com pouco retoque. A matéria prima desses instrumentos inclui rochas vulcânicas, quartzo, quartizito, calcário e sílex (Toth e Schick, 2009). A indústria lítica seguinte é conhecida como Acheulense, e apareceu pela primeira vez no leste da África há cerca de 1,75 milhão de anos (Lepre et al., 2011; Beyene et al., 2013; Yravedra et al., 2017). lascado de ambos os lados. A indústria lítica seguinte é chamada de Mousteriense e surgiu por volta de 300 mil anos. Seu grande diferencial foi o uso da técnica levallois. Ela consiste na preparação de um núcleo através da retirada de lascas, normalmente resultando em um núcleo com uma face plana e outra convexa. Essa técnica permite maior quantidade e variedade de formas, que se ajustam de forma mais flexível à tarefa a ser executada (Schlanger, 1996). Por fim, a indústria do paleolítico superior, surgida por volta de 60 mil anos na África e $40 \mathrm{mil}$ anos na Europa e Ásia, é caracterizada pela enorme flexibilização dos tipos de instrumentos produzidos, de acordo com tradições culturais próprias no tempo e no espaço. Há abundância de instrumentos compostos, combinando ossos, conchas, marfim e rochas, tais como projéteis, arpões, anzóis e agulhas. A presença de lâminas e microlíticos passou a ser mais comum, aumentando a parte cortante em relação à quantidade de matéria prima utilizada. Além disso, muitos dos instrumentos produzidos combinavam a funcionalidade com marcas simbólicas, tais como gravuras, desenhos e pinturas. 
Shea (2017) propõe que antes de 1,7 MAA os hominínios, assim como outros primatas, eram usuários ocasionais de ferramentas. Entre 1,7 e 0,3 MAA passamos a ser usuários habituais de indústria lítica, e depois de 0,3 MAA passamos a ser usuários obrigatórios de instrumentos. Nesse sentido, é impossível pensar humanos modernos sem a presença de instrumentos. Todavia, esse alto grau de dependência dos instrumentos em humanos modernos foi adquirido por um processo gradual, que ocorreu a partir das primeiras ferramentas de pedras há 3,3 MAA e continuou se modificando até o presente, refletindo as mudanças na capacidade cognitiva dos membros da nossa linhagem.

Outro aspecto crucial para essa segunda transição na nossa linhagem, e que está diretamente atrelado à definição do gênero Homo, é a expansão do cérebro. O Homo habilis é a primeira espécie da nossa linhagem a apresentar evidência de expansão cerebral. A evidência mais antiga dessa espécie vem de fragmentos de maxila e dentes achados em estratos de 2,4 MAA em Hadar, Etiópia (Kimbel et al., 1996). Para muitos pesquisadores a evidência fóssil dessa espécie é consistente com duas espécies ou grupos morfológicos distintos (Leakey et al., 2012; Anton et al., 2014; Spoor et al., 2015).
O primeiro tipo é mais grácil com caixa craniana ao redor de 550 $\mathrm{cm}^{3}$, dentes pequenos e faces relativamente gráceis em relação a formas robustas de australopitecíneos, sendo representado pelo crânio KNM-ER 1813. Já o outro tipo é representado pelo crânio KNM-ER 1470 (Leakey, 1973), e apresenta tamanho craniano maior $\left(750 \mathrm{~cm}^{3}\right)$, mas com face e dentes mais robustos. Alguns classificam esse tipo como Homo rudolfensis ou Kenyanthropus rudolfensis. O aumento absoluto do cérebro é visto de forma definitiva com o surgimento do Homo erectus no leste da África há 1,9 MAA (KNMER 3733), apresentando caixa craniana de cerca de $850 \mathrm{~cm}^{3}$ (Lepre e Kant, 2015). De forma geral, os $H$. erectus tem crânios baixos e longos, constrição pós-orbital, tórus supra-orbital, tórus nucal e formato pentagonal do crânio visto da parte posterior. Essa espécie tem caixa craniana com média de 950 $\mathrm{cm}^{3}$, apresentando molares relativamente pequenos em comparação com australopitecíneos (Rightmire, 2004). É importante destacar que há variabilidade nas medidas de capacidade craniana em $H$. erectus, como pode ser visto no crânio de Illeret, Quênia, com $690 \mathrm{~cm}^{3}$ e no crânio OH-9, Tanzânia, com $1067 \mathrm{~cm}^{3}$, ambos datados de 1,5 MAA. Essa variação sugere para alguns autores um di- 
morfismo sexual acentuado (Spoor et al., 2007), porém isso também pode ser devido a variações regionais da espécie. O Quociente de Encefalização (QE), que é uma razão entre massa do cérebro e massa corpórea, não cresceu tanto em Homo erectus, já que o aumento da caixa craniana aconteceu concomitante ao aumento da massa corpórea. O aumento significativo do QE foi observado mais tardiamente na morfologia do Homo heidelbergensis, que apareceu pela primeira vez em torno $600 \mathrm{mil}$ anos na Europa, representado pela mandíbula de Mauer, Alemanha (Wagner et al., 2010), e na África, representado pelo crânio de Bodo, Etiópia (Clark et al., 1994). A capacidade craniana expandiu para valores médios de cerca de $1200 \mathrm{~cm}^{3}$ nessa espécie. O Homo heidelbergensis provavelmente deu origem aos neandertais na Europa e aos sapiens na África, que apresentaram uma expansão ainda maior da caixa craniana para cerca de $1400 \mathrm{~cm}^{3}$ (Rightmire, 2004). Do surgimento do Homo habilis há 2,4 MAA até o surgimento do Homo sapiens há 200 mil anos, houve uma expansão da caixa craniana de cerca de $400 \mathrm{~cm}^{3}$ para $1400 \mathrm{~cm}^{3}$. Embora estejamos tratando aqui da expansão do volume craniano na nossa linhagem, o gênero Homo também apresenta exemplos de espécies com manutenção de um cérebro pequeno.
Esse é o caso do Homo naledi, encontrado na África do Sul e datado em cerca de 300 mil anos, apresentando volume craniano de 600 $\mathrm{cm}^{3}$ (Berger et al., 2015; Dirks et al., 2017). Outro caso notável é o do Homo floresienses, encontrado na Ilha das Flores, Indonésia, datado entre 100 e 60 mil anos, e com um volume craniano de $400 \mathrm{~cm}^{3}$ (Brown et al., 2004; Sutikna et al., 2016). Uma das explicações para esse último achado é a diminuição do cérebro devido ao nanismo insular, que é uma forte pressão seletiva para diminuição do tamanho de mamíferos devido à escassez de recursos e baixa competição interespecífica em ilhas (Aiello, 2010). Essas exceções à tendência de expansão do cérebro na linhagem Homo mostram que há maior flexibilidade adaptativa na nossa linhagem do que imaginávamos antes. Além disso, a evolução da nossa linhagem não é uma trajetória linear, sendo caracterizada por diversidade de espécies e por diversos episódios de extinção.

As razões evolutivas para a expansão do cérebro na nossa linhagem podem ser explicadas por três grupos de hipóteses, que não são necessariamente excludentes. A primeira explicação é relacionada a uma mudança na qualidade do alimento, e, portanto, na base energética alimentar no gênero Homo. O cérebro é um órgão extremamente 
dispendioso em termos energéticos, consumindo de 20 a $25 \%$ de toda a energia em repouso do nosso corpo. Sustentar energicamente esse órgão demanda um balanço energético diferente do visto em outros primatas. Aiello e Wheeler (1995) propuseram a hipótese do tecido caro, sugerindo que o aumento do tamanho do cérebro precisou ser acompanhado pela diminuição do gasto energético em outros sistemas do corpo, no nosso caso o sistema digestório. É importante destacar que essa explicação não é consenso entre os pesquisadores, já que alguns deles mostraram ausência de correlação entre tamanho do cérebro e do intestino em mamíferos (Navarrete et al. 2011). De fato, o tamanho do trato intestinal em humanos é significativamente menor que em outros primatas, o que é coerente com uma dieta energicamente mais rica. Uma outra possibilidade é que na verdade os Homo lidaram com esse aumento energético diminuindo a massa muscular e aumentando o tecido adiposo (Leonard et al., 2003).

$\mathrm{O}$ uso do fogo também seria um elemento importante para a melhora na qualidade nutricional da dieta (Wrangham, 2009). No entanto, a evidência mais segura de uso de fogo para hominínios é na caverna de Wonderwerck, África do Sul, datada de 1 MAA (Berna et al., 2012), enquanto uma evidência mais generalizada do uso do fogo só é documentada na Europa por volta de 400 mil anos atrás (Roebroeks e Villa, 2011). Em síntese, uma reestruturação energética ocorreu no gênero Homo para lidar com o enorme aumento de energia gerado pela expansão do cérebro, demandando uma dieta energeticamente mais rica. Discutiremos aqui evidências empíricas que dão sustentação para uma mudança de qualidade de dieta associada com a expansão do cérebro

A incorporação de uma quantidade maior de tecido animal na dieta humana é no momento a explicação mais aceita para a melhora da qualidade nutricional da nossa dieta por volta de 2 MAA. A análise de uma assembleia lítica de 63 artefatos escavados em Kanjera South, Quênia, e datada em 2 MAA mostrou que 23 deles tiveram marcas microscópicas de uso. Em 70\% desses instrumentos há marcas de uso para processamento de plantas, tais como órgãos de reserva de subsolo, madeiras e gramíneas, ao passo que $30 \%$ delas apresentam marcas de uso em tecido animal (Lemorini et al., 2014). Concentrações de ossos quebrados com marcas de corte a partir de 2 MAA indicam clara participação humana na acumulação e processamento desse material. Por outro lado, é difícil imaginar que os pri- 
meiros Homo, sem uma tecnologia elaborada nem uma estrutura biológica apropriada para a caça, pudessem obter carne em um ambiente repleto de animais preparados para lidar com a predação. Shipman (1986) foi a primeira pesquisadora a mostrar evidências de que $Z$ os primeiros Homo não eram caçadores, mas sim carniceiros, ao mostrar que havia marcas de dentes de animais embaixo das marcas de corte de instrumentos de pedra, ou seja, os animais tiveram acesso primário às carcaças. Análises mais recentes têm mostrado que tanto os animais como os humanos acessaram as mesmas carcaças, sugerindo um modelo de que os primeiros a acessarem a carcaça foram os felinos, depois os humanos e por fim outros carniceiros, tais como as hienas (Pante et al., 2012). Mais uma vez o conjunto fóssil de Kanjera South, Quênia, datado em 2 MAA traz evidências importantes sobre essa questão. A acumulação de fauna nesse sítio mostrou que, por um lado, humanos transportaram e consumiram primariamente bovídeos de pequeno e médio porte, ao passo que, por outro lado, a grande quantidade de cabeças de bovídeos parece indicar uma procura por tecido cerebral através da carniçagem (Ferraro et al., 2013). Outros pesquisadores, em contraste, defendem que os humanos tiveram um papel primário no acesso ao tecido animal, talvez através de uma carniçagem mais ativa, afugentando os animais logo depois que eles matavam suas presas, mas antes que eles a consumissem. Em uma assembleia fóssil de 1,84 MAA na Tanzânia (FLK Zinj) foi possível detectar sinais de consumo primário de animais pelos humanos (Dominguez-Rodrigo et al., 2014). De qualquer maneira, seja pela carniçagem ou pela caça, as evidências arqueológicas se acumulam no sentido de que a carne foi primordial para a expansão do cérebro dos primeiros Homo por volta de 2 MAA. Do ponto de vista nutricional, Cordain et al. (2001) ressaltaram a importância do consumo de ácidos graxos, tais como o ácido docosahexaenóico (DHA) e o ácido araquidônico (AA), para o crescimento do cérebro, mostrando que eles são encontrados essencialmente em tecidos animais.

Outra linha de evidência empírica para o consumo de carne é a morfologia e a composição química do esmalte dental dos primeiros Homo. A topografia dos dentes de $H$. habilis e $H$. erectus indicam que as cúspides nessas espécies são mais proeminentes comparadas às de australopitecíneos, sugerindo uma adaptação morfológica para a quebra de alimentos elásticos e difíceis de quebrar (tough), tal como a carne (Ungar, 2004). Análises de elementos quí- 
micos encontrados no esmalte dos dentes são também bons indicadores do consumo de carne. As quantidades de bário, estrôncio e cálcio do esmalte indicam que os primeiros Homo consumiam mais carne que os australopitecíneos robustos do sul da África (Balter et al., 2012).

Por fim, as hipóteses energéticas para explicar o aumento do cérebro estão associadas a uma importante evidência fóssil: a diminuição dos dentes molares. Essa diminuição ocorre de forma mais acentuada em Homo erectus, e depois novamente no surgimento do Homo sapiens. A diminuição do dente representa uma economia de energia significativa, pois também está associada à diminuição da estrutura facial, mandibular e muscular (Ungar, 2012). Estudos genéticos em humanos modernos calcularam que a houve uma inativação do gene da miosina (MYH16), que é responsável pela constituição dos músculos da mastigação, há cerca de 2,4 MAA, resultando em perda de potência mastigatória (Steadman et al., 2004). A explicação para essa diminuição é que o processamento do alimento passou a ser realizado antes da ingestão, seja por quebra mecânica realizada por instrumentos (Zink e Lieberman, 2016) ou por redução química e mudança de consistência gerada pelo fogo (Wrangham,
2009).

O segundo conjunto de hipóteses para explicar a expansão do cérebro é relacionado ao ambiente social. Para os autores proponentes dessa hipótese, a qualidade da dieta é uma condição necessária, mas não suficiente para explicar expansão do cérebro. A real vantagem seletiva para compensar o alto custo energético do cérebro está ligada às vantagens cognitivas que o cérebro proporciona. A principal base empírica dessas hipóteses é de que em primatas, principalmente os antropoides, existe uma correlação entre o tamanho do neocórtex, que é a área externa do cérebro responsável pela articulação e processamento dos dados, e o tamanho do grupo social, sendo que essa correlação também pode ser observada, a grosso modo, com o volume total do cérebro. Essa correlação é explicada pela importância da capacidade cognitiva para lidar com a complexidade social em primatas, que é constituída de relações entre indivíduos em circunstâncias de forrageio, dominância, reprodução e proteção. Em humanos modernos, o tamanho do neocórtex prediz um tamanho de grupo de 150 pessoas, que fariam parte do círculo social de uma pessoa (Dunbar, 1998, 2009). Evidências empíricas de mudanças de organização social têm sido observadas em material arqueológico antigo. Assembleias 
fósseis acumuladas há 2 MAA em Olduvai, Tanzânia, indicam que os primeiros Homo procuravam abrigos em bosques próximos de fontes de água, cercados por áreas abertas, caracterizando a formação de campos-base. Eles traziam carcaças de animais e consumiam recursos vegetais e água nesses locais, como uma área de refúgio (Magill et al., 2015). É importante destacar, no entanto, que a organização social nesse primeiro momento era diferente da organização social em humanos modernos. A análise da distribuição do material nesses campos-base de 2 MAA mostrou uma mancha única de ossos e instrumentos, diferindo do observado em acampamentos de sociedades caçadoras-coletoras atuais, que apresentam múltiplas agregações, representando as famílias nucleares (Dominguez-Rodrigo e Cobo-Sanchéz, 2017). Da mesma forma, a história de vida dos primeiros Homo ainda era mais semelhante a dos grandes símios do que a dos humanos modernos (Da-Gloria, 2014). Dentes de espécimes de Java e do Lago Turkana na África mostram que o primeiro molar ainda erupcionava cedo em $H$. erectus, indicando que eles tinham um crescimento e amadurecimento mais rápidos do que humanos modernos (Dean et al., 2001). Um padrão de organização social e de histó- ria de vida moderno só irá aparecer definitivamente com o surgimento do Homo sapiens (ver próxima seção). Esses dados mostraram que uma mudança de organização social surgiu com o início da expansão do cérebro na linhagem Homo, aproximando-se gradativamente do padrão atual conforme o cérebro foi se expandindo ao longo do Pleistoceno. Esse processo de mudança de organização social pode estar ligado a uma estratégia adaptativa centrada na ocupação permanente de áreas abertas de savana, em um estilo de vida caçador-coletor, e em um aumento do tamanho dos grupos e do grau de cooperação entre os indivíduos do nosso gênero.

Por fim, um terceiro conjunto de hipóteses para explicar a expansão do cérebro está ligado à adaptação ambiental. Reconstruções ambientais têm mostrado que os últimos 6 MAA tem testemunhado um ressecamento e esfriamento global, que na África gerou um aumento das áreas abertas de savana (Cerling et al., 2011). Uma hipótese especialmente relevante aqui é a de seleção natural pela variabilidade. Essa hipótese é baseada em dados ambientais que mostram um aumento da flutuação climática durante o Pleistoceno, entre 2,6 MAA e 10 mil anos atrás. Uma das implicações de viver em um ambiente altamente variável é a seleção 
natural para versatilidade adaptativa e plasticidade comportamental (Potts, 2012). Além da evidência ambiental, dados de microdesgaste dentário de Homo erectus dão suporte à hipótese de variabilidade ambiental. O microdesgaste dentário é medido através de uma técnica que quantifica o relevo da superfície oclusal do dente, permitindo inferências sobre a consistência e textura do alimento consumido. Como o microdesgaste registra as marcas no dente feitas poucos dias antes da morte, a análise de vários indivíduos pode fornecer a variabilidade alimentar da espécie ao longo dos anos. Dados de microdesgaste de hominínios indicam que o traço marcante da dieta de $H$. erectus é a variabilidade da textura dos alimentos consumidos, sugerindo uma alta adaptabilidade a diferentes ambientes (Ungar et al., 2006).

Em síntese, a segunda grande transição da linhagem hominínia envolve o surgimento do gênero Homo e a aquisição de um pacote adaptativo que inclui ferramentas, caixa craniana expandida e diminuição dental. Por outro lado, essas aquisições não ocorreram simultaneamente no registro arqueológico. Ferramentas de pedra surgiram primeiro, seguidas do início da expansão do cérebro, e, por fim, a diminuição dos dentes, sendo que essas três caracterís- ticas logo ficaram associadas na estratégia adaptativa dos Homo erectus. A partir desse momento, esses três aspectos foram gradativamente evoluindo até chegar ao estado atual em humanos modernos.

\section{Terceira transição: pensamento simbólico e suas implicações comportamentais}

A terceira transição na nossa linhagem é relacionada ao surgimento do Homo sapiens há cerca de 200 mil anos. Evidências morfológicas dos primeiros sapiens são baseadas no crânio do Omo I da Formação Kibish na Etiópia datado de 195 mil anos (McDougall et al., 2005) e do crânio de Herto, Etiópia, datado de 160 mil anos (White et al., 2003). Fósseis de formas precursoras de nossa espécie têm sido achadas na África, como é o caso dos fósseis de Jebel Irhoud, Marrocos, datados de 315 mil anos $(\mathrm{Hu}-$ blin et al., 2017). Os sapiens anatomicamente modernos são caracterizados por apresentarem fossas caninas, arcada supraciliar pouco acentuada, queixo, face pouco projetada, testa alta e calota globulosa, abertura nasal mais estreita e dentes molares pequenos e simples. Já o pós-crânio, em relação a formas arcaicas viventes naquele período, é caracterizado por quadril e troncos estreitos, maior estatura, antebraço e tíbia mais longos e ossos da mão mais gráceis 
(Schwartz e Tattersall, 2010). Embora essa caracterização é suficiente para distinguir morfológicamente nossa espécie, o traço definidor de humanos modernos está relacionado ao comportamento de nossa espécie (Shea, 2011). A maioria dos pesquisadores em evolução humana assume que esse traço comportamental distinto dos humanos modernos é relacionado ao pensamento simbólico, isto é, à capacidade de produção de redes de símbolos, envolvendo graus elevados de imaginação e abstração.

A maior dificuldade para detectar pensamento simbólico em nossa linhagem é a natureza da evidência arqueológica necessária para comprovar esse traço. Nesse aspecto, três indicadores de pensamento simbólico podem ser usados como evidência: adornos corporais, arte pré-histórica e rituais funerários. Em relação aos adornos, aqueles mais associados ao simbolismo são os fragmentos de ocre e as conchas perfuradas, que provavelmente foram usados para pintura corporal e ornamentação, respectivamente. Na Caverna de Blombos, África do Sul, foi encontrado ocre dentro de um recipiente feito de concha, datado em estratos de 100 mil anos (Henshilwood et al. 2011). Na mesma caverna há conchas perfuradas para produção de adornos em estratos de 75 mil anos (Vanhaeren et al., 2013).
Essas conchas perfuradas parecem ter tido uma distribuição por toda a África e Oriente Médio nesse período, pois elas também foram encontradas na Grotte des Pigeons, Morrocos, há 82 mil anos (Bouzougarr et al., 2007) e em Israel há cerca de 100 mil anos (Vanhaeren et al., 2006). Minerais de múltiplas cores trazidos de áreas distantes e com marcas de queima foram encontrados em sítios em Israel entre 100 e 135 mil anos (d'Errico et al., 2010). Na África, a presença de indicadores de comportamento humano moderno podem ser recuados até 164 mil anos em Pinacle Point, África do Sul, com evidência de uso de ocre, de exploração de ambiente costeiro e de presença de lâminas líticas (Marean et al., 2007).

Em relação à produção de arte, há evidências associadas com sapiens tanto de pinturas rupestres como de arte em substrato portátil. Em Howiesons Poort, África do Sul, há pinturas em ovos de avestruz com conotação estética há 60 mil anos (Texier et al., 2010). Outro indicador de pensamento abstrato são os desenhos geométricos, tais como aqueles gravados em suporte de pedra na Caverna de Blombos há 75 mil anos (Henshilwood et al., 2009). Fica claro por essa revisão da evidência, que sinais de comportamento simbólico apareceram na África após 
o surgimento do Homo sapiens há cerca de 200 mil anos (McBrearty e Brooks, 2000). Esse mesmo comportamento é observado com bastante intensidade na Europa a partir de 40 mil anos, o que é tradicionalmente chamado de revolução do paleolítico superior, e está associado à expansão dos sapiens vindos da África por volta de 50 mil anos. Por exemplo, figuras humanas femininas feitas de marfim com seios avantajados e sem cabeça, chamadas de vênus e com clara conotação simbólica, foram achadas na Caverna de Hohle Fels, Alemanha, e datadas em $35 \mathrm{mil}$ anos (Conard, 2009). Já as pinturas de Altamira e Altexerri B na Espanha e Chauvet na França tem idades entre 35 e 40 mil anos, logo na chegada dos sapiens na Europa (Pike et al., 2012). Já na Ásia, nas cavernas de Sulawesi, Indonésia, pinturas de mão e de animais foram encontradas nas paredes com datação de 40 mil anos (Aubert et al., 2014), mostrando sinais da expansão de uma espécie com um comportamento simbólico já estabelecido.

Quanto ao modo de depositar os mortos, os sapiens são a única espécie com claros sinais de ocorrência de rituais funerários. Embora a evidência arqueológica seja bastante esparsa durante o Pleistoceno, a partir de $40 \mathrm{mil}$ anos há diversos exemplos de enterra- mentos de sapiens com elaborados acompanhamentos funerários. O exemplo mais emblemático é o de Sungir, Russia, datado de 30 mil anos (Nalawade-Chavan et al., 2014). Esse sítio inclui sepultamentos adultos e de crianças com extensivo acompanhamento funerário, incluindo contas de marfim e dentes de animais (Pettitt, 2010). A presença universal de enterramentos ritualizados em Homo sapiens parece indicar que a partir desse momento os indivíduos de nossa espécie passaram a ser capazes de criar mundos imaginados que ultrapassam a realidade concreta, incluindo seres sobrenaturais e realidades imaginadas após a morte, como é observado extensamente na mitologia religiosa de sociedades tradicionais atuais.

Nas últimas décadas, o entendimento do pensamento simbólico na nossa linhagem tem ganhado um conjunto novo de evidências empíricas advindas do estudo de sítios ocupados por Homo neanderthalensis. Essa espécie, ou subespécie como alguns pesquisadores preferem classificá-la, viveu na Eurasia em altas latitudes, apresentando uma morfologia diferente dos sapiens, com diversas adaptações para climas frios. Neandertais têm crânios longos e baixos, arcada supraciliar projetada, ausência de queixo, coque nucal, face medial proeminente 
com alargamento dos sinos e da abertura nasal, espaço retromolar, dentes molares taurodontes e dentes anteriores relativamente grandes. O pós-crânio apresenta tórax em forma de barril, bacia e ombros largos, tíbia e antebraço curtos, ossos do corpo bastante robustos e estatura mais baixa. Além do que historicamente se associa ao comportamento neandertal, ligado a uma estratégia de vida com alta demanda física, esse grupo também apresenta cérebros iguais ou maiores que os dos sapiens, e como veremos a seguir estão associados a comportamentos antes restritos aos sapiens.

Materiais arqueológicos de diversos sítios neandertais na Europa apresentam evidências de marcas de cortes nas extremidades de ossos de corvos e aves de rapina para a retirada de penas e garras, possivelmente para serem usados como adornos corporais (Finlayson et al., 2012; Morin e Laroulandie, 2012). Já na Caverna de Fumane, Itália, foi encontrado uma concha marinha datada de cerca de 45 mil anos que foi transportada por quase 100 $\mathrm{km}$ e banhada de ocre no seu exterior, possivelmente para uso como adorno por neandertais (Peresani et al., 2013). Sítios de neandertais na península ibérica apresentam evidência de conchas marinhas perfuradas e pintadas com pigmentos minerais amarelos e ver- melhos há cerca 50 mil anos (Zilhão et al., 2010). Ainda mais antigo, minerais vermelhos e amarelos em recipientes e conchas perfuradas e pintadas foram encontrados na Cueva de los Aviones, Espanha, e datados de 115 a 120 mil anos (Hoffman et al., 2018a). Além disso, contrário ao pensamento tradicional que apenas sapiens utilizavam instrumentos polidos feitos de osso, um instrumento de osso polido chamado de lissoir foi encontrado na França com data de 50 mil anos e foi possivelmente usado por neandertais para tratamento de couro (Soressi et al., 2013). No sítio La Quina, França, foram encontrados três fragmentos de crânio humanos datado em cerca de 50 mil anos e usados como instrumentos por neandertais (Verna e d'Errico, 2011). No que diz respeito ao pensamento abstrato, uma gravação na rocha com padrões geométricos foi encontrada na Caverna de Gorham, Espanha, com mais de 40 mil anos (RodríguezVidal et al., 2014). Recentemente, pinturas em três cavernas na Espanha feitas com pigmento vermelho foram datadas em pelo menos 64,8 mil anos, mostrando pela primeira vez que neandertais também são capazes desse tipo de manifestação (Hoffmann et al., 2018b). Enterramentos dos mortos também foram feitos por neandertais, embora haja pesquisadores que ainda 
contestem essa interpretação (Gargett, 1999; Sandghate et al., 2011). Entre aqueles que defendem esses enterramentos, o caso do esqueleto de La Chapelle-aux-Saints, França, é usado como evidência do enterramento intencional em neandertais (Rendu et al., 2014). De fato, há algumas dezenas de casos de enterramento de neandertais, porém é preciso destacar que essas deposições não apresentam o elaborado acompanhamento funerário observado em enterramentos sapiens depois de 40 mil anos. Em síntese, as evidências de pensamento simbólico em neandertais cresceram enormemente nas últimas décadas, a ponto de se assemelharem e para outros até ultrapassarem as evidências disponível para sapiens. Por esse raciocínio, não é surpreendente que sapiens e neandertais tenham hibridizado e deixado descendentes férteis, como mostraram estudos de DNA (Green et al., 2010), atestando assim que a diferença entre essas duas formas foi menor do que imaginávamos.

A evidência material do pensamento simbólico parece não ter aparecido abruptamente nos sapiens e nos neandertais. Embora escassos, existem evidências incipientes de pensamento simbólico em espécies mais antigas de hominínios. O uso de conchas de rio para alimentação, fabricação de instrumentos e suporte para desenhos geométricos abstratos foi atribuída ao Homo erectus de Java há $500 \mathrm{mil}$ anos (Joordens et al., 2015). Outro exemplo é a figura de Berekhat Ram, possivelmente um torso de uma mulher feita em pedra encontrada em estratos de cerca de 230 mil anos em Israel (d'Errico e Nowell, 2000). Ainda mais antiga, a vênus de Tan-Tan, achada no Marrocos em estratos de 400 mil anos, também pode ser uma possível figura humana trabalhada (Bednarik, 2003). Em camadas de 200 a 250 mil anos há evidência de uso de ocre em um sítio arqueológico na Holanda, advindo de hematita importada de fontes a quilómetros de distância (Robroecks et al., 2012) e em um sítio arqueológico na Zâmbia, África, há 200 mil anos (Barham, 2002). Embora esses objetos sejam bastante esparsos e não apresentem uma ligação inquestionável com o pensamento simbólico, é possível que a capacidade em articular redes de símbolos tenha aparecido no ancestral comum de sapiens e neandertais há mais de 500 mil anos.

A capacidade de articular redes de símbolos de forma a criar realidades abstratas tem diversas consequências comportamentais e faz parte da maneira como caracterizamos os humanos modernos. Essas redes de símbolos são essenciais para a existência de fenômenos como a linguagem, a arte, a reli- 
gião e a cultura. A linguagem humana, por exemplo, é entendida por muitos como um traço crucial para o surgimento e expansão do Homo sapiens. As evidências físicas desse traço, no entanto, são muito escassas. No que tange à capacidade física de produção de sons, neandertais e sapiens parecem ser igualmente capazes, já que ambos apresentam ossos do hioide similares, que é o osso responsável pelo ancoramento de músculos da laringe (D'Anastasio et al., 2013). Já em uma abordagem genética, a sequência do gene FOXP2, que é relacionado à fala em humanos modernos, é similar em neandertais e sapiens e até mesmo em espécies arcaicas como os denisovanos (Krause et al., 2007). Por outro lado, foi detectada uma variação em uma área reguladora desse gene que só é encontrada em humanos modernos, embora não em todos (Maricic et al., 2013). Ainda não há um consenso sobre o momento exato que apareceu a linguagem humana moderna, e se ela foi compartilhada com neandertais.

Outra implicação do pensamento simbólico é o desenvolvimento da cultura. Embora alguns biólogos identifiquem cultura em animais, tais como em chimpanzés, o desenvolvimento da cultura em humanos moderno, entendida aqui como acumulação de conhe- cimento que é transferido socialmente, está ligada a mecanismos bioculturais complexos. $\mathrm{O}$ advento da cultura em $H$. sapiens possibilitou a existência de uma herança cultural independente da herança biológica, gerando maior acúmulo de conhecimento ambiental e social, e maior flexibilidade adaptativa (Richerdson e Boyd, 2005). O momento exato que essa herança cultural atingiu a configuração atual ainda é assunto de debate, mas é certo que está ligada ao desenvolvimento do pensamento simbólico na nossa linhagem. Outro elemento importante para o surgimento da cultura humana moderna são mudanças na história de vida, isto é, a quantidade de energia alocada em cada uma das fases de vida do organismo. Os traços característicos da história de vida de humanos modernos, tais como o longo período de crescimento e desenvolvimento e o aumento da longevidade, parecem ter atingido o padrão atual só depois da última expansão sapiens pelo globo há 50 mil anos. Esse aspecto pode ter sido crucial para distinguir sapiens de neandertais, pois estes últimos ainda tinham um desenvolvimento mais acelerado, o que pode ter prejudicado a capacidade deles em transmitir e acumular conhecimento cultural (Da-Gloria, 2014).

As hipóteses para explicar evo- 
lutivamente o desenvolvimento do pensamento simbólico na nossa linhagem podem ser divididas em dois grupos. O primeiro deles se refere às hipóteses intrínsecas, preconizando que mutações biológicas afetando o cérebro de indivíduos da nossa linhagem desencadearam as mudanças comportamentais encontradas em humanos modernos. Um exemplo dessa abordagem é a hipótese neural defendida por Richard Klein, propondo que por volta de 50 mil anos uma mudança biológica surgida ao acaso trouxe enorme vantagem adaptativa para uma linhagem de Homo sapiens, gerando mudança comportamental e consequente expansão para fora da África (Klein, 2008). Essa hipótese, porém, tem sido questionada pela ausência de evidências da natureza biológica dessa mudança e pela abundância de evidências mostrando que o pensamento simbólico apareceu de fato há pelo menos 200 mil anos. De qualquer forma, é bastante plausível que mudanças biológicas que alteraram nossa cognição tenham feito parte do desenvolvimento da capacidade de pensar simbolicamente na nossa linhagem. O segundo conjunto de hipóteses é chamado de extrínsecas, e está ligado a mudanças ambientais ocorridas nos últimos 500 mil anos. Os defensores dessas ideias acreditam que o aumento da variabilidade climá- tica exerceu uma forte pressão seletiva para a flexibilização comportamental na nossa linhagem, resultando no surgimento do pensamento simbólico e da herança cultural (Scholz et al. 2007, Potts, 2012). Uma variante dessa hipótese ambiental se refere à mudança no ambiente social da nossa linhagem. Segundo Dunbar (2003), grupos sociais maiores exerceram uma pressão sobre a cognição humana, resultando no aparecimento da linguagem simbólica como um facilitador da comunicação em contexto social. É importante enfatizar que tanto as hipóteses intrínsecas como as extrínsecas são complementares, já que em mudanças adaptativas, tanto a alteração biológica ao acaso como a pressão seletiva ambiental ocorrem simultaneamente.

\section{Considerações finais}

Este texto discutiu as principais mudanças evolutivas na linhagem hominínia, organizando essas transições em três momentos, que culminaram no surgimento dos humanos modernos. A primeira transição se refere ao surgimento da bipedia e à diminuição dos caninos, que ocorreram entre 7 e 2 MAA. A segunda transição consistiu no surgimento das ferramentas de pedra, na expansão do cérebro e na diminuição dos dentes, que ocorreram entre 3,5 e 2 
MAA, e estão atreladas ao surgimento do gênero Homo. Por fim, a terceira transição se refere ao surgimento do pensamento simbólico há cerca de 200 mil anos e de suas implicações comportamentais, tais como cultura, linguagem, arte e religião. Essa sequência de eventos evolutivos mostra a importância de traçar a história particular de uma linhagem para entender a sua configuração biológica atual. No caso humano, essa trajetória é ainda mais relevante, pois, durante o nosso processo de evolução, a herança cultural foi se tornando mais proeminente, chegando ao ponto de influir ativamente no comportamento e na constituição biológica de nossa linhagem.

O delineamento dessas transições tem como objetivo fornecer uma estrutura empírica e evolutiva para o desenvolvimento de reflexões sobre a evolução biológica, o advento da cultura e suas implicações para o comportamento humano atual. Nesse ponto, fazse o diálogo com a obra de Paulo Abrantes sobre a evolução cultural (Abrantes e Almeida, 2011) e a evolução da cooperação (Abrantes, 2014b), ambas utilizando a teoria de dupla herança. Segundo essa abordagem, a espécie humana apresenta tanto uma herança cultural como uma herança biológica, que, apesar de possuírem mecanismos independentes, tem se influ- enciado mutuamente ao longo da nossa evolução. Este artigo visa complementar essa discussão, fornecendo bases empíricas e evolutivas para reflexão sobre quando esses dois mecanismos de herança passaram a se influenciar mutuamente. Tentativamente, é possível propor que o fortalecimento da herança cultural na nossa linhagem ocorreu com o surgimento do gênero Homo há cerca de 2,5 MAA, mas só atingiu seu estágio atual com a expansão do Homo sapiens para fora da África há 50 mil anos. Nesse sentido, a presença significativa de uma herança cultural na nossa linhagem é relativamente recente, embora seja resultado de um longo encadeamento de eventos históricos.

Por fim, outro ponto de diálogo deste artigo com a obra de Paulo Abrantes é a discussão sobre natureza e cultura. Abrantes (2014c) observa que a dicotomia natureza/cultura é um importante entrave para o diálogo entre as ciências humanas e as biológicas, especialmente no Brasil. Nesse ponto, compartilho a visão de que a separação entre biologia e cultura tem uma origem na história acadêmica das disciplinas envolvidas (e.g., biologia, ciências médicas, ciências sociais, psicologia, filosofia), e que essa separação não representa a complexidade da evolução e dos comportamentos hu- 
manos. Nesse sentido, este texto texto busca sensibilizar pesquisabusca contribuir para que se dis- dores da área biológica para a imsolva a dicotomia natureza e cul- portância da herança cultural na tura, uma vez que os humanos atu- nossa linhagem, e sensibilizar pesais são resultado de um processo quisadores das humanidades para complexo de evolução biocultural, a relevância das raízes biológicas que foi construído evolutivamente do comportamento humano. ao longo da nossa linhagem. Esse

\section{Referências}

ABRANTES PC (org.). 2011. Filosofia da Biologia. Porto Alegre: Artmed. ABRANTES PC (org.). 2014a. Evolução humana. Santa Maria: Universidade Federal de Santa Maria. Ciência E Ambiente, vol. 48.

ABRANTES PC. 2014b. Conflito e cooperação na evolução humana. Ciência E Ambiente, 48:289-301.

ABRANTES PC. 2014c. Natureza e cultura. Ciência E Ambiente, 48:721.

ABRANTES PC, Almeida FPL. 2011. Evolução humana: a teoria da dupla herança. In: ABRANTES PC (org.). Filosofia da Biologia. Porto Alegre: Artmed. p. 261-295.

AIELLO, LC. 2010. Five years of Homo floresiensis. American Journal of Physical Anthropology, 142:167-179.

AIELLO, LC.; WHEELER, P. 1995. The expensive-tissue hypothesis: the brain and the digestive system in human and primate evolution. Current Anthropology, 36:199-221.

ALMÉCIJA, S.; TALLMAN, M.; ALBA, DM.; PINA, M.; MOYÀ-SOLÀ, S.; JUNGERS, WL. 2013. The femur of Orrorin tugenensis exhibits morphometric affinities with both Miocene apes and later hominins. Nature Communications, 4:2888.

AMARAL, LQ. 1996. Loss of body hair, bipedality and thermoregulation. Comments on recent papers in the journal of human evolution. Journal of Human Evolution, 30:357-366.

AMARAL, LQ. 2013. Bipedalismo: solução para carregar crias, correlacionada com a redução de pelos. Revista da Biologia, 11(1):19-27. ANTÓN, SC.; POTTS R.; AIELLO, LC. 2014. Evolution of early Homo: An integrated biological perspective. Science, 345(6192):1236828. 
Aubert M, Brumm A, Ramli M, Sutikna T, Saptomo EW, et al. 2014. Pleistocene cave art from Sulawesi, Indonesia. Nature, 514:223227.

BALTER, V.; BRAGA, J.; TÉLOUK, P.; THACKERAY, JF. 2012. Evidence for dietary change but not landscape use in South African early hominins. Nature, 489:558-560.

BAMFORD, MK.; SENUT, B.; PICKFORD, M. 2013. Fossil leaves from the Upper Miocene Lukeino Formation (Baringo, Kenya). Geobios, 46:253-272.

BARHAM, LS. 2002. Systematic pigment use in the Middle Pleistocene of south-central Africa. Current Anthropology, 43:181-190.

BEDNARIK, RG. 2003. A figurine from the African Acheulian. Current Anthropology, 44(3):405-413.

BEGUN, DR. 2016. The real planet of the apes: a new story of human origins. Princeton: Princeton University Press.

BEGUN, DR.; NARGOLWALLA, MC.; KORDOS, L. 2012. European Miocene hominids and the origin of the African ape and human clade. Evolutionary Anthropology, 21:10-23.

BERGE, C.; GOULARAS, D. 2010. A new reconstruction of Sts 14 pelvis (Australopithecus africanus) from computed tomography and three-dimensional modeling techniques. Journal of Human Evolution, 58:262-272.

BERGER, LR.; HAWKS, J.; DE RUITER, DJ.; CHURCHILL, SE.; SCHMID, P.; et al. 2015. Homo naledi, a new species of the genus Homo from the Dinaledi Chamber, South Africa. eLife, 4:e09560.

BERNA, F.; GOLDBERG, P.; HORWITZ, LK.; BRINK, J.; HOLT, S.; et al. 2012. Microstratigraphic evidence of in situ fire in the Acheulean strata of Wonderwerk Cave, Northern Cape province, South Africa. Proceedings of the National Academy of Sciences of the United States of America, 109(20):E1215-E1220.

BEYENE, Y.; KATOH, S.; WOLDEGABRIEL, G.; HART, WK.; UTO, K.; et al. 2013. The characteristics and chronology of the earliest Acheulean at Konso, Ethiopia. Proceedings of the National Academy of Sciences of the United States of America, 110:1584-1591.

BLEUZE, M. 2012. Proximal femoral diaphyseal cross-sectional geometry in Orrorin tugenensis. HOMO - Journal of Comparative Human Biology, 63:153-166.

BOESCH, C.; HEAD, J.; ROBBINS, MM. 2009. Complex tool sets for honey extraction among chimpanzees in Loango National Park, 
Gabon. Journal of Human Evolution, 56:560-569.

BOUZOUGGAR, A.; BARTON, N.; VANHAEREN, M.; D'ERRICO, F.; COLLCUTT, S.; et al. 2007. 82,000-year-old shell beads from North Africa and implications for the origins of modern human behaviour. Proceedings of the National Academy of Sciences of the United States of the America, 104:9964-9969.

BRAMBLE, DM.; LIEBERMAN, DE. 2004. Endurance running and the evolution of Homo. Nature, 432:345-352.

BROWN, P.; SUTIKNA, T.; MORWOOD, MJ.; SOEJONO, RP.; JATMIKO; et al. 2004. A new small-bodied hominin from the Late Pleistocene of Flores, Indonesia. Nature, 431:1055-1061.

BRUNET, M.; GUY, F.; PILBEAM, D.; MACKAYE, HT.; LIKIUS, A.; et al. 2002. A new hominid from the Upper Miocene of Chad, Central Africa. Nature, 418: 145-151.

BRUNET, M.; GUY, F.; PILBEAM, D.; LIEBERMAN, DE.; LIKIUS, A.; et al. 2005. New material of the earliest hominid from the Upper Miocene of Chad. Nature, 434:752-755.

CARVALHO, S.; BIRO, D.; CUNHA, E.; HOCKINGS, K.; MCGREW, WC.; et al. 2012. Chimpanzee carrying behaviour and the origins of human bipedality. Current Biology, 22(6):R180-181.

CERLING, TE.; WYNN, JG.; ANDANJE, SA.; BIRD, MI.; KORIR, DK.; et al. 2011. Woody cover and hominin environments in the past 6 million years. Nature, 476:51-56.

CLARK, JD.; DE HEINZELIN, J.; SCHICK, KD.; HART, WK.; WHITE, TD.; et al. 1994. African Homo erectus: old radiometric ages and young Oldowan assemblages in the Middle Awash valley, Ethiopia. Science, 264:1907-1910.

CLAXTON, AG.; HAMMOND, AS.; ROMANO, J.; OLEINIK, E.; DESILVA, JM. 2016. Virtual reconstruction of the Australopithecus africanus pelvis Sts 65 with implications for obstetrics and locomotion. Journal of Human Evolution, 99:10-24.

CONARD, NJ. 2009. A female figurine from the basal Aurignacian of Hohle Fels Cave in southwestern Germany. Nature, 459:248-252.

CORDAIN, L.; WATKINS, BA.; MANN, NJ. 2001. Fatty acid composition and energy density of foods available to African hominids. World Review of Nutrition and Dietetics, 90:144-161.

DA-GLORIA, P. 2009. Seria a teoria da evolução darwiniana domínio exclusivo dos biólogos? Implicações da evolução biológica para as ciências humanas. Revista da Biologia, 3:1-5. 
DA-GLORIA, P. 2014. Evolução da história de vida humana. Ciência E Ambiente, 48:79-93.

D’ANASTASIO, R.; WROE, S.; TUNIZ, C.; MANCINI, L.; CESANA, DT.; et al. 2013. Micro-biomechanics of the Kebara 2 hyoid and its implications for speech in Neanderthals. PLoS ONE, 8(12):e82261.

DARWIN, C. 1871. The descent of Man. London: John Murray.

DÁVID-BARRETT, T.; DUNBAR, RIM. 2016. Bipedality and hair loss in human evolution revisited: The impact of altitude and activity scheduling. Journal of Human Evolution, 94:72-82.

DEAN, MC.; LEAKEY, MG.; REID, D.; SCHRENK, F.; SCHWARTZ, GT.; et al. 2001. Growth processes in teeth distinguish modern humans from Homo erectus and earlier hominins. Nature, 414:628631.

DERICQUEBOURG, P.; PERSON, A.; SÉGALEN, L.; PICKFORD, M.; SENUT, B.; FAGEL, N. 2015. Environmental significance of Upper Miocene phosphorites at hominid sites in the Lukeino Formation (Tugen Hills, Kenya). Sedimentary Geology, 327:43-54.

D'ERRICO, F.; NOWELL, A. 2000. A new look at the Berekhat Ram figurine: Implications for the origins of symbolism. Cambridge Archaeological Journal, 10(1):123-167.

D’ERRICO, F.; SALOMON, H.; VIGNAUD, C.; STRINGER, C. 2010. Pigments from the Middle Palaeolithic levels of Es-Skhul (Mount Carmel, Israel). Journal of Archaeological Science, 37:3099-3110.

DESILVA, JM.; HOLT, KG.; CHURCHILL, SE.; CARLSON, KJ.; WALKER, CS.; et al. 2013. The lower limb and mechanics of walking in Australopithecus sediba. Science, 340: 1232999-1 - 1232999-5.

DINGWALL, HJ.; HATALA, KG.; WUNDERLICH, RE.; RICHMOND, BG. 2013. Hominin stature, body mass, and walking speed estimates based on 1.5 million-year-old fossil footprints at Ileret, Kenya. Journal of Human Evolution, 64:556-568.

DIRKS, PHGM.; ROBERTS, EM.; HILBERT-WOLF, H.; KRAMERS, JD.; HAWKS, J.; et al. 2017. The age of Homo naledi and associated sediments in the Rising Star Cave, South Africa. eLife, 6:e24231.

DOMÍNGUEZ-RODRIGO, M.; BUNN, HT.; YRAVEDRA, J. 2014. A critical re-evaluation of bone surface modification models for inferring fossil hominin and carnivore interactions through a multivariate approach: Application to the FLK Zinj archaeofaunal assemblage (Olduvai Gorge, Tanzania). Quaternary International, 322323:32-43. 
DOMÍNGUEZ-RODRIGO, M.; COBO-SÁNCHEZ, L. 2017. A spatial analysis of stone tools and fossil bones at FLK Zinj 22 and PTK I (Bed I, Olduvai Gorge, Tanzania) and its bearing on the social organization of early humans. Palaeogeography, Palaeoclimatology, Palaeoecology, 488:21-34.

DUNBAR, RIM. 1998. The social brain hypothesis. Evolutionary Anthropology, 6:178-190.

DUNBAR, RIM. 2003. The social brain: Mind, language and society in evolutionary perspective. Annual Review of Anthropology, 32:163181.

DUNBAR, RIM. 2009. The social brain hypothesis and its implications for social evolution. The social brain hypothesis and its implications for social evolution. Annals of Human Biology, 36(5):562-572.

FERRARO, JV.; PLUMMER, TW.; POBINER, BL.; OLIVER, JS.; BISHOP, LC.; et al. 2013. Earliest archaeological evidence of persistent hominin carnivory. PLoS ONE, 8(4):e62174.

FINLAYSON, C.; BROWN, K.; BLASCO, R.; ROSELL, J.; NEGRO, JJ.; et al. 2012. Birds of a feather: Neanderthal exploitation of raptors and corvids. PLOS ONE, 7:e45927.

FREEMAN, D. 1974. The evolutionary theories of Charles Darwin and Hebert Spencer. Current Anthropology, 15:211-237.

FUSS, J.; SPASSOV, N.; BEGUN, DR.; BÖHME, M. 2017. Potential hominin affinities of Graecopithecus from the Late Miocene of Europe. PLoS ONE, 12(5):e0177127.

GALIK, K.; SENUT, B.; PICKFORD, M.; GOMMERY, D.; TREIL, J.; et al. 2004. External and internal morphology of the BAR 1002'00 Orrorin tugenensis femur. Science, 305:1450-1453.

GANI, MR.; GANI, ND. 2011. River-margin habitat of Ardipithecus ramidus at Aramis, Ethiopia 4.4 million years ago. Nature Communications, 2:602.

GARGETT, RH. 1999. Middle Paleolithic burial is not a dead issue: the view from Qafzeh, Saint-Cézaire, Kebara, Amud, and Dederiyeh. Journal of Human Evolution, 37:27-90.

GREEN, RE.; KRAUSE, J.; BRIGGS, AW.; MARICIC, T.; STENZEL, U.; et al. 2010. A draft sequence of the Neandertal genome. Science, 328:710-722.

GREENFIELD, LO. 1998. Canine tip wear in male and female anthropoids. American Journal of Physical Anthropology, 107:87-96.

HAILE-SELASSIE, Y. 2001. Late Miocene hominids from the Middle 
Awash, Ethiopia. Nature, 412:178-181.

HAILE-SELASSIE, Y.; SUWA, G.; WHITE, TD. 2004. Late Miocene teeth from Middle Awash, Ethiopia, and early hominid dental evolution. Science, 303:1503-1505

HARMAND, S.; LEWIS, JE.; FEIBEL, CS.; LEPRE, CJ.; PRAT, S.; et al. 2015. 3.3-million-year-old stone tools from Lomekwi 3, West Turkana, Kenya. Nature, 521:310-315.

HARRIS, E. 2015. Ancestors in our genome: the new science of human evolution. New York: Oxford University Press.

HASLAM, M. 2014. On the tool use behavior of the bonobo-chimpanzee last common ancestor, and the origins of hominine stone tool use. American Journal of Primatology, 76:910-918.

HASLAM, M.; LUNCZ, LV.; STAFF, RA.; BRADSHAW, F.; OTTONI, EB. Falótico T. 2016. Pre-Columbian monkey tools. Current Biology, 26:R521-R522.

HENSHILWOOD, CS.; D'ERRICO, F.; VAN NIEKERK, KL.; COQUINOT, Y.; JACOBS, Z.; et al. 2011. A 100,000-year-old ochre-processing workshop at Blombos Cave, South Africa. Science, 334:219-221.

HENSHILWOOD, CS.; D’ERRICO, F.; WATTS, I. 2009. Engraved ochres from the Middle Stone Age levels at Blombos Cave, South Africa. Journal of Human Evolution, 57:27-47.

HOFFMANN, DL.; ANGELUCCI, DE.; VILLAVERDE, V.; ZAPATA, J.; ZILHÃO, J. 2018a. Symbolic use of marine shells and mineral pigments by Iberian Neandertals 115,000 years ago. Science Advances, 4 :eaar 5255.

HOFFMANN, DL.; STANDISH, CD.; GARCÍA-DIEZ, M.; PETTITT, PB.; MILTON, JA.; et al. 2018b. U-Th dating of carbonate crusts reveals Neandertal origin of Iberian cave art. Science, 359:912-915.

HUBLIN, J.; BEN-NCER, A.; BAILEY, SE.; FREIDLINE, SE.; NEUBAUER, S.; et al. 2017. New fossils from Jebel Irhoud, Morocco and the pan-African origin of Homo sapiens. Nature, 546:289-292.

HUNT, KD. 1996. The postural feeding hypothesis: an ecological model for the evolution of bipedalism. South African Journal of Science, 92:77-90.

HUXLEY, TH. 1963. Evidence as to Man's place in Nature. London: Williams and Norgate.

HYLANDER, WL. 2013. Functional links between canine height and jaw gape in catarrhines with special reference to early hominins. American Journal of Physical Anthropology, 150:247-259. 
ISHIDA, H.; PICKFORD, M. 1997. A new Late Miocene hominoid from Kenya: Samburupithecus kiptalami gen. et sp. nov. Comptes Rendus de l'Académie des Sciences, Series IIA, Earth and Planetary Science, 325:823-829.

JABLONKA, E.; LAMB, MJ. 2005. Evolution in four dimensions: genetic, epigenetic, behavioral and symbolic variation in the history of life. Cambridge: MIT Press.

JOORDENS, JCA.; D'ERRICO, F.; WESSELINGH, FP.; MUNRO, S.; DE VOS, J.; et al. 2015. Homo erectus at Trinil on Java used shells for tool production and engraving. Nature 518:228-231.

KEITH, A. 1948. A new theory of human evolution. London: Watts \& Company.

KIMBEL, WH.; DELEZENE, LK. 2009. "Lucy" redux: a review of research on Australopithecus afarensis. Yearbook of Physical Anthropo$\log y, 52: 2-48$.

KIMBEL, WH.; WALTER, RC.; JOHANSON, DC.; REED, KE.; ARONSON, JL.; ASSEFA, Z.; et al. 1996. Late Pliocene Homo and Oldowan tools from the Hadar Formation (Kada Hadar Member), Ethiopia. Journal of Human Evolution, 31:549-561.

KLEIN, RG. 2008. Out of Africa and the evolution of human behavior. Evolutionary Anthropology, 17:267-281.

KRAUSE, J.; LALUEZA-FOX, C.; ORLANDO, L.; ENARD, W.; GREEN, RE.; et al. 2007. The derived FOXP2 variant of modern humans was shared with Neandertals. Current Biology, 17:1908-1912.

KUNIMATSU, Y.; NAKATSUKASA, M.; SAWADA, Y.; SAKAI, T.; SANEYOSHI, M.; et al. 2016. A second hominoid species in the early Late Miocene fauna of Nakali (Kenya). Anthropological Science, 124(2):75-83.

LANGERGRABER, KE.; PRÜFER, K.; ROWNEY, C.; BOESCH, C.; CROCKFORD, C.; et al. 2012. Generation times in wild chimpanzees and gorillas suggest earlier divergence times in great ape and human evolution. Proceedings of the National Academy of Sciences of the United States of the America, 109(39):15716-15721.

LEAKEY, LSB.; TOBIAS, PV.; NAPIER, JR. 1964. A new species from the genus Homo from Olduvai Gorge. Nature, 202:7-9.

LEAKEY, REF. 1973. Evidence for an Advanced Plio-Pleistocene Hominid from East Rudolf, Kenya. Nature, 242:447-450.

LEAKEY, MG.; SPOOR, F.; DEAN, MC.; FEIBEL, CS.; ANTÓN, SC.; et al.. 2012. New fossils from Koobi Fora in northern Kenya confirm 
taxonomic diversity in early Homo. Nature, 488:201-204.

LE FUR, S.; FARA, E.; MACKAYE, HT.; VIGNAUD, P.; BRUNET, M. 2014. Toros-Menalla (Chad, $7 \mathrm{Ma}$ ), the earliest hominin-bearing area: How many mammal paleocommunities? Journal of Human Evolution, 69:79-90.

LEMORINI, C.; PLUMMER, TW.; BRAUN, DR.; CRITTENDEN, AN.; DITCHFIELD, PW.; et al. 2014. Old stones' song: Use-wear experiments and analysis of the Oldowan quartz and quartzite assemblage from Kanjera South (Kenya). Journal of Human Evolution, 72:10-25.

LEONARD, WR.; ROBERTSON, ML.; SNODGRASS, JJ.; KUZAWA, CW. 2003. Metabolic correlates of hominid brain evolution. Comparative Biochemistry and Physiology - Part A. Molecular E Integrative Physiology, 135:5-15.

LEPRE, CJ.; ROCHE, H.; KENT, DV.; HARMAND, S.; QUINN, RL.; et al. 2011. An earlier origin for the Acheulean. Nature, 477:82-85.

LEPRE, CJ.; KENT, DV. 2015. Chronostratigraphy of KNM-ER 3733 and other Area 104 hominins from Koobi Fora. Journal of Human Evolution, 86:99-111.

LOVEJOY, CO. 1981. The origin of Man. Science, 211(4480):341-350.

LOVEJOY, CO. 2005a. The natural history of human gait and posture. Part 1. Spine and pelvis. Gait and Posture, 21:95-112.

LOVEJOY, CO. 2005b. The natural history of human gait and posture.

Part 2. Hip and thigh. Gait and Posture, 21:113-124.

LOVEJOY, CO. 2007. The natural history of human gait and posture.

Part 3. The knee. Gait and Posture, 25:325-341.

LOVEJOY, CO. 2009. Reexamining human origins in light of Ardipithecus ramidus. Science, 326: 74e1-e8.

LOVEJOY, CO.; SUWA, G.; SPURLOCK, L.; ASFAW, B.; WHITE, TD. 2009a. The pelvis and femur of Ardipithecus ramidus: The emergence of upright walking. Science, 326: 71.

LOVEJOY, CO.; SIMPSON, SW.; WHITE, TD.; ASFAW, B.; SUWA, G. 2009b. Careful climbing in the Miocene: the forelimbs of Ardipithecus ramidus and humans are primitive. Science, 326:70.

MAGILL, CR.; ASHLEY, GM.; DOMÍNGUEZ-RODRIGO, M.; FREEMAN, KH. 2015. Dietary options and behavior suggested by plant biomarker evidence in an early human habitat. Proceedings of the National Academy of Sciences of the United States of the America, 113(11): 2874-2879. 
MAREAN, CW.; BAR-MATTHEWS, M.; BERNATCHEZ, J.; FISHER, E.; GOLDBERG, P.; et al. 2007. Early human use of marine resources and pigment in South Africa during the Middle Pleistocene. Nature, 449:905-908.

MARICIC, T.; GÜNTHER, V.; GEORGIEV, O.; GEHRE, S.; ĆURLIN, M.; et al. 2013. A recent evolutionary change affects a regulatory element in the human FOXP2 gene. Molecular Biology and Evolution, 30(4):844-852.

MAYR, E. 1961. Cause and effect in biology. Science, 134(3489):15011506.

MCBREARTY, S.; BROOKS, AS. 2000. The revolution that wasn't: a new interpretation of the origin of modern human behaviour. Journal of Human Evolution, 39:453-563.

MCDOUGALL, I.; BROWN, FH.; FLEAGLE, JG. 2005. Stratigraphic placement and age of modern humans from Kibish, Ethiopia. Nature, 433:733-736.

MCPHERRON, SP.; ALEMSEGED, Z.; MAREAN, CW.; WYNN, JG.; REED, D.; et al. 2010. Evidence for stone-tool-assisted consumption of animal tissues before 3.39 million years ago at Dikika, Ethiopia. Nature, 466:857-860.

MEYER, D.; EL-HANI, CN. 2005. Evolução: o sentido da biologia. São Paulo: Editora Unesp.

MORIN, E.; LAROULANDIE, V. 2012. Presumed symbolic use of diurnal raptors by Neanderthals. PLOS ONE, 7(3):e32856.

NALAWADE-CHAVAN, S.; MCCULLAGH, J.; HEDGES, R. 2014. New hydroxyproline radiocarbon dates from Sungir, Russia, confirm Early Mid Upper Palaeolithic burials in Eurasia. PLoS ONE, 9(1):e76896.

NAVARRETE, A.; VAN SCHAIK, CP.; ISLER, K. 2011. Energetics and the evolution of human brain size. Nature, 480:91-93.

NEVES, WA.; RANGEL JR, MJ.; MURRIETA, RSS. (Orgs.). 2015. Assim caminhou a humanidade. São Paulo: Palas Athena.

O'NEILL, MC.; LEE, L.; DEMES, B.; THOMPSON, NE.; LARSON, SG.; et al. 2015. Three-dimensional kinematics of the pelvis and hind limbs in chimpanzee (Pan troglodytes) and human bipedal walking. Journal of Human Evolution, 86:32-42.

PANTE, MC.; BLUMENSCHINE, RJ.; CAPALDO, SD.; SCOTT, RS. 2012. Validation of bone surface modification models for inferring fossil hominin and carnivore feeding interactions, with reapplication to FLK 22, Olduvai Gorge, Tanzania. Journal of Human Evolution, 


\section{3:395-407.}

PATTERSON, N.; RICHTER, DJ.; GNERRE, S.; LANDER, ES.; REICH, D. 2006. Genetic evidence for complex speciation of humans and chimpanzees. Nature, 441:1103-1108.

PERESANI, M.; VANHAEREN, M.; QUAGGIOTTO, E.; QUEFFELEC, A.; D'ERRICO, F. 2013. An ochered fossil marine shell from the Mousterian of Fumane Cave, Italy. PLoS ONE, 8(7):e68572.

PETTITT, P. 2010. The Palaeolithic origins of human burial. New York: Routledge.

PICKFORD, M.; SENUT, B. 2001. The geological and faunal context of Late Miocene hominid remains from Lukeino, Kenya. Comptes Rendus de l'Académie des Sciences - Series IIA - Earth and Planetary Science, 332:145-152.

PICKFORD, M.; SENUT, B. 2005. Hominoid teeth with chimpanzee and gorilla-like features from the Miocene of Kenya: implications for the chronology of ape-human divergence and biogeography of Miocene hominoids. Anthropological Science, 113:95-102.

PICKFORD, M.; SENUT, B. Gommery D, Treil J. 2002. Bipedalism in Orrorin tugenensis revealed by its femora. Comptes Rendus Palevol, 1:191-203.

PICKFORD, M.; SENUT, B.; MORALES, J.; BRAGA, J. 2008. First hominoid from the Late Miocene of Niger. South African Journal of Science, 104:337-339.

PIKE, AWG.; HOFFMANN, DL.; GARCÍA-DIEZ, M.; PETTITT, PB.; ALCOLEA, J.; et al. 2012. U-series dating of Paleolithic art in 11 caves in Spain. Science, 336:1409-1413.

PLAVCAN, JM. 2012. Sexual size dimorphism, canine dimorphism, and male-male competition in primates. Where do humans fit in? $\mathrm{Hu}$ man Nature, 23:45-67.

PLAVCAN, JM.; LOCKWOOD, CA.; KIMBEL, WH.; LAGUE, MR.; HARMON, EH. 2005. Sexual dimorphism in Australopithecus afarensis revisited: How strong is the case for a human-like pattern of dimorphism? Journal of Human Evolution, 48: 313-320.

PONTZER, H.; RAICHLEN, DA.; SOCKOL, MD. 2009. The metabolic cost of walking in humans, chimpanzees, and early hominins. Journal of Human Evolution, 56:43-54.

PONTZER, H.; RAICHLEN, DA.; RODMAN, OS. 2014. Bipedal and quadrupedal locomotion in chimpanzees. Journal of Human Evolution, 66:64-82. 
POTTS, R. 2012. Evolution and environmental change in early human prehistory. Annual Review of Anthropology, 41:151-167.

PRADO-MARTINEZ, J.; SUDMANT, PH.; KIDD, JM.; LI, H.; KELLEY, JL.; et al. 2013. Great ape genetic diversity and population history. Nature, 499:471-475.

PROFFITT, T.; LUNCZ, LV.; FALÓTICO, T.; OTTONI, EB.; TORRE, I.; HASLAM, M. 2016. Wild monkeys flake stone tools. Nature, 539:8588.

REED, DL.; LIGHT, JE.; ALLEN, JM.; KIRCHMAN, JJ. 2007. Pair of lice lost or parasites regained: the evolutionary history of anthropoid primate lice. BMC Biology, 5:7.

RENDU, W.; BEAUVAL, C.; CREVECOEUR, I.; BAYLE. P.; BALZEAU, A.; et al. 2014. Evidence supporting an intentional Neandertal burial at La Chapelle-aux-Saints. Proceedings of the National Academy of Sciences of the United States of the America, 111(1):81-86.

RICHERSON, PJ.; BOYD, R. 2005. Not by genes alone: how culture transform human evolution. Chicago: University of Chicago Press.

RICHMOND, BG.; JUNGERS, WL. 2008. Orrorin tugenensis femoral morphology and the evolution of hominin bipedalism. Science, 319:1662-1665.

RIDLEY M. 2004. Evolution. Malden, MA: Blackwell Science Ltd. $3^{\text {rd }}$ ed.

RIGHTMIRE, GP. 2004. Brain size and encephalization in Early to MidPleistocene Homo. American Journal of Physical Anthropology, 124:109_ 123.

ROACH, NT.; VENKADESAN, M.; RAINBOW, MJ.; LIEBERMAN, DE. 2013. Elastic energy storage in the shoulder and the evolution of high-speed throwing in Homo. Nature, 498:483-486.

ROCHE, D.; SÉGALEN, L.; SENUT, B.; PICKFORD, M. 2013. Stable isotope analyses of tooth enamel carbonate of large herbivores from the Tugen Hills deposits: Palaeoenvironmental context of the earliest Kenyan hominids. Earth and Planetary Science Letters, 381:3951.

RODRÍGUEZ-VIDAL, J.; D’ERRICO, F.; PACHECO, FG.; BLASCO, R.; ROSELL, J.; et al. 2014. A rock engraving made by Neanderthals in Gibraltar. Proceedings of the National Academy of Sciences of the United States of the America, 111(37):13301-13306.

ROEBROEKS, W.; SIER, MJ.; NIELSEN, TK.; DE LOECKER, D.; PARÉS, JM.; et al. 2012. Use of red ochre by early Neandertals. Procee- 
dings of the National Academy of Sciences of the United States of the America, 109(6):1889-1894.

ROEBROEKS, W.; VILLA, P. 2011. On the earliest evidence for habitual use of fire in Europe. Proceedings of the National Academy of Sciences of the United States of the America, 108(13):5209-5214.

ROGERS, AR.; ILTIS, D.; WOODING, S. 2004. Genetic variation at the MC1R locus and the time since loss of human body hair. Current Anthropology, 45(1):105-108.

RUSSO, GA.; KIRK, EC. 2017. Another look at the foramen magnum in bipedal mammals. Journal of Human Evolution, 105:24-40

RUVUOLO, M. 1997. Molecular phylogeny of the hominoids: inferences from multiple independent DNA sequence data sets. Molecular Biology and Evolution, 14(3):248-265.

RUXTON, GD.; WILKINSON, DM. 2011. Thermoregulation and endurance running in extinct hominins: WHEELER's models revisited. Journal of Human Evolution, 61:169-175.

SANDGATHE, DM.; DIBBLE, HL.; GOLDBERG, P.; MCPHERRON, SP. 2011. The Roc de Marsal Neandertal child: A reassessment of its status as a deliberate burial. Journal of Human Evolution, 61:243253.

SCALLY, A.; DURBIN, R. 2012. Revising the human mutation rate: implications for understanding human evolution. Nature Review, Genetics, 13:745-753.

SCHLANGER, N. 1996. Understanding Levallois: lithic technology and cognitive archaeology. Cambridge Archaeological Journal, 6(2):231254.

SCHMID, P. 2004. Functional interpretation of the Laetoli footprints. In: MELDRUM, DJ.; HILTON, CE. (eds.). From Biped to Strider. Boston: Springer. p. 49-62.

SCHWARTZ, JH.; TATTERSALL, I. 2010. Fossil evidence for the origin of Homo sapiens. Yearbook of Physical Anthropology, 53:94-121.

SEMAW, S.; RENNE, P.; HARRIS, JWK.; FEIBEL, CS.; BERNOR, RL.; et al. 1997. 2.5-million-year-old stone tools from Gona, Ethiopia. Nature, 385:333-336.

SENUT, B.; PICKFORD, M.; GOMMERY, D.; MEIN, P.; CHEBOI, K.; COPPENS, Y. 2001. First hominid from the Miocene (Lukeino Formation, Kenya). Comptes Rendus de l'Académie des Sciences, Series IIA, Earth and Planetary Science, 332:137-144.

SHIPMAN, P. 1986. Scavenging or hunting in early hominids. American 
Anthropologist, 88:27-13.

SHEA, JJ. 2011. Homo sapiens is as Homo sapiens was: Behavioral variability versus "behavioral modernity" in Paleolithic archaeology. Current Anthropology, 52(1):1-35.

SHEA, JJ. 2017. Occasional, obligatory, and habitual stone tool use in hominin evolution. Evolutionary Anthropology, 26:200-217.

SCHOLZ, CA.; JOHNSON, TC.; COHEN, AS.; KING, JW.; PECK, JA.; et al. 2007. East African megadroughts between 135 and 75 thousand years ago and bearing on early-modern human origins Proceedings of the National Academy of Sciences of the United States of the America, 104:16416-16421.

SOCKOL, MD.; RAICHLEN, DA.; PONTZER, H. 2007. Chimpanzee locomotor energetics and the origin of human bipedalism. Proceedings of the National Academy of Sciences of the United States of the America, 30:12265-12269.

SORESSI, M.; MCPHERRON, SP.; LENOIR, M.; DOGANDZIĆ, T.; GOLDBERG, P.; et al. 2013. Neandertals made the first specialized bone tools in Europe. Proceedings of the National Academy of Sciences of the United States of the America, 110(35):14186-14190.

SPONHEIMER, M.; ALEMSEGED, Z.; CERLING, TE.; GRINE, FE.; KIMBEL, WH.; et al. 2013. Isotopic evidence of early hominin diets. Proceedings of the National Academy of Sciences of the United States of the America, 110(26):10513-10518.

SPOOR, F.; GUNZ, P.; NEUBAUER, S.; STELZER, S.; SCOTT, N.; et al. 2015. Reconstructed Homo habilis type $\mathrm{OH} 7$ suggests deep-rooted species diversity in early Homo. Nature, 519:83-86.

SPOOR, F.; LEAKEY, MG.; GATHOGO, PN.; BROWN, FH.; ANTÓN, SC.; et al. 2007. Implications of new early Homo fossils from Ileret, east of Lake Turkana, Kenya. Nature, 448:688-691.

STANFORD, CB. 2006. Arboreal bipedalism in wild chimpanzees: implications for the evolution of hominid posture and locomotion. American Journal of Physical Anthropology, 129:225-231.

STEDMAN, HH.; KOZYAK, BW.; NELSON, A.; THESIER, DM.; SU, LT.; et al. 2004. Myosin gene mutation correlates with anatomical changes in the human lineage. Nature, 428:415-418.

SUTIKNA, T.; TOCHERI, MW.; MORWOOD, MJ.; SAPTOMO, EW.; JATMIKO; et al. 2016. Revised stratigraphy and chronology for Homo floresiensis at Liang Bua in Indonesia. Nature, 532:366-369.

SUWA, G.; KONO, RT.; KATOH, S.; ASFAW, B.; BEYENE, Y. 2007. A 
new species of great ape from the late Miocene epoch in Ethiopia. Nature, 448:921-924.

SUWA, G.; ASFAW, B.; KONO, RT.; KUBO, D.; LOVEJOY, CO.; WHITE, TD. 2009a. The Ardipithecus ramidus skull and its implications for hominid origins. Science, 326:68.

SUWA, G.; KONO, RT.; SIMPSON, SW.; ASFAW, B.; LOVEJOY, CO.; WHITE, TD. 2009b. Paleobiological implications of the Ardipithecus ramidus dentition. Science, 326:94-99.

TATTERSALL, I. 2009. The fossil trail: how we know what we think we know about human evolution. New York: Oxford University Press.

TEXIER, P.; PORRAZ, G.; PARKINGTON, J.; RIGAUD, J.; POGGENPOEL, C.; et al. 2010. A Howiesons Poort tradition of engraving ostrich eggshell containers dated to 60,000 years ago at Diepkloof Rock Shelter, South Africa. Proceedings of the National Academy of Sciences of the United States of the America, 107(14):6180-6185.

THORPE, SKS.; HOLDER, RL.; CROMPTON, RH. 2007. Origin of human bipedalism as an adaptation for locomotion on flexible branches. Science, 316:1328-1331.

TOTH, N.; SCHICK, K. 2009. The Oldowan: the tool making of early hominins and chimpanzees compared. Annual Review of Anthropology, 38:289-305.

UNGAR, P. 2004. Dental topography and diets of Australopithecus afarensis and early Homo. Journal of Human Evolution, 46:605-622.

UNGAR P. 2012. Dental evidence for the reconstruction of diet in African early Homo. Current Anthropology, 53(S6):S318-S329.

UNGAR, PS.; GRINE, FE.; TEAFORD, MF. 2006. Diet in early Homo: a review of the evidence and a new model of adaptive versatility. Annual Review of Anthropology, 35:209-228.

VANHAEREN, M.; D'ERRICO, F.; STRINGER, C.; JAMES, SL.; TODD, J.; MIENIS, HK. 2006. Middle Palaeolithic shell beads in Israel and Algeria. Science, 312:1785-1788.

VANHAEREN, M.; D'ERRICO, F.; VAN NIEKERK, KL.; HENSHILWOOD, CS.; ERASMUS, RM. 2013. Thinking strings: Additional evidence for personal ornament use in the Middle Stone Age at Blombos Cave, South Africa. Journal of Human Evolution, 64:500-517.

VERNA, C.; D'ERRICO, F. 2011. The earliest evidence for the use of human bone as a tool. Journal of Human Evolution, 60:145-157.

VILLMOARE, B.; KIMBEL, WH.; SEYOUM, C.; CAMPISANO, CJ.; DIMAGGIO, E.; ROWAN, J.; et al. 2015. Early Homo at 2.8 Ma from 
Ledi-Geraru, Afar, Ethiopia. Science, 347(6228):1352-1355.

WAGNER, GA.; KRBETSCHEK, M.; DEGERING, D.; BAHAIN, J.; SHAO, Q.; et al. 2010. Radiometric dating of the type-site for Homo heidelbergensis at Mauer, Germany. Proceedings of the National Academy of Sciences of the United States of the America, 107(46): 1972619730.

WARD, CV.; KIMBEL, WH.; JOHANSON, DC. 2011. Complete fourth metatarsal and arches in the foot of Australopithecus afarensis. Science, 331:750-753.

WHEELER, PE. 1984. The evolution of bipedality and loss of functional body hair in hominids. Journal of Human Evolution, 13:91-98.

WHEELER, PE. 1991. The thermoregulatory advantages of hominid bipedalism in open equatorial environments; the contribution of increased convective heat loss and cutaneous evaporative cooling. Journal of Human Evolution, 21:107-115.

WHEELER, PE. 1993. The influence of stature and body form on hominid energy and water budgets; a comparison of Australopithecus and early Homo physiques. Journal of Human Evolution, 24:13-28. WHITE, TD.; ASFAW, B.; DEGUSTA, D.; GILBERT, H.; RICHARDS, GD.; et al. 2003. Pleistocene Homo sapiens from Middle Awash, Ethiopia. Nature, 423:742-747.

WHITE, TD.; ASFAW, B.; BEYENE, Y.; HAILE-SELASSIE, Y.; LOVEJOY, CO.; et al. 2009. Ardipithecus ramidus and the paleobiology of early hominids. Science, 326: 75-86.

WHITE, TD.; LOVEJOY, CO.; ASFAW, B.; CARLSON, JP.; SUWA, G. 2015. Neither chimpanzee nor human, Ardipithecus reveals the surprising ancestry of both. Proceedings of the National Academy of Sciences of the United States of the America, 112(16):4877-4884.

WILSON, AC.; SARICH, VM. 1969. A molecular time scale for human evolution. Proceedings of the National Academy of Sciences of the United States of the America, 63(4):1088-1093.

WOLDEGABRIEL, G.; AMBROSE, SH.; BARBONI, D.; BONNEFILLE, R.; BREMOND, L.; et al. 2009. The geological, isotopic, botanical, invertebrate, and lower vertebrate surroundings of Ardipithecus ramidus. Science, 326: 65e1-65e5.

WOLPOFF, MH.; HAWKS, J.; SENUT, B.; PICKFORD, M.; AHERN, J. 2006. An ape or the ape: Is the Toumaï cranium TM 266 a hominid? PaleoAnthropology, 2006:36-50.

WOOD, B.; HARRISON, T. 2011. The evolutionary context of the first 
hominins. Nature, 470:347-352.

WRANGHAM, R. 2009. Catching fire: how cooking made us human. New York, NY: Basic Books.

WYNN, JG.; SPONHEIMER, M.; KIMBEL, WH.; ALEMSEGED, Z.; REED, K.; et al. 2013. Diet of Australopithecus afarensis from the Pliocene Hadar Formation, Ethiopia. Proceedings of the National Academy of Sciences of the United States of the America, 110(26):10495-10500. YRAVEDRA, J.; DIEZ-MARTÍN, F.; EGELAND, CP.; MATÉ-GONZÁLEZ, MA.; PALOMEQUE-GONZÁLEZ, JF.; et al. 2017. Flk west (Lower Bed II, Olduvai Gorge, Tanzania): A new early Acheulean site with evidence for human exploitation of fauna. Boreas: An International Journal of Quaternary Research, 46(4):816-830.

ZILHÃO, J.; ANGELUCCI, DE.; BADAL-GARCÍA, E.; D’ERRICO, F.; DANIEL, F; et al. 2010. Symbolic use of marine shells and mineral pigments by Iberian Neandertals. Proceedings of the National Academy of Sciences of the United States of America, 107:1023-1028. ZINK, KD.; LIEBERMAN, DE. 2016. Impact of meat and Lower Palaeolithic food processing techniques on chewing in humans. Nature, 531:500-503.

ZOLLIKOFER, CPE.; PONCE DE LEÓN, MS.; LIEBERMAN, DE.; GUY, F.; PILBEAM, D.; et al. 2005. Virtual cranial reconstruction of Sahelanthropus tchadensis. Nature, 434: 755-759. 
